\title{
Mansion Tax: The Effect of Transfer Taxes on the Residential Real Estate Market ${ }^{\dagger}$
}

\author{
By WoJcIEch KopczuK ANd David MunRoE*
}

\begin{abstract}
Using discontinuities in housing transaction taxes in New York and New Jersey we find robust price bunching. Incidence for transactions local to the notch falls on sellers, with no evidence of evasion. The volume of missing transactions above the notch exceeds those bunching (beyond the usual extensive-margin response), indicating incentives for buyers and sellers not to transact (market unravels). The possibility of unraveling affects interpretation and estimation of bunching. Away from the threshold, we find increased discounts and weaker relationship between listing and sale prices. Equilibrium bargaining framework highlights that taxation affects the ultimate allocation in this search market. (JEL H71, R21, R31)
\end{abstract}

\begin{abstract}
Jurchasing real estate is a time consuming and complicated process with large financial stakes and potentially important frictions. Beyond the price, a typical transaction involves many associated costs, including broker's fees, inspection costs, legal fees, title insurance, mortgage application and insurance fees, and moving costs. In this paper, we rely on a particular type of cost-transfer taxes that are imposed on the value of real estate transactions - - to understand how frictions affect the functioning of this market.

Our objective is fourfold. Real estate transfer taxation is common, and given the importance of this market it is of interest to understand the empirical implications of such taxes. Second, we take advantage of variation in tax incentives and data on both transactions and listings in order to gain better understanding of the importance of search and matching frictions in this market. Third, we use this context to develop a framework for understanding tax incidence and efficiency costs of transaction taxes in search and matching markets more generally. Other contexts where similar issues arise are labor markets and financial transaction taxes. Fourth, our theory and
\end{abstract}

\footnotetext{
* Kopczuk: Department of Economics and School of International and Public Affairs, Columbia University, 420 West 118th Street, New York, NY 10025, National Bureau of Economic Research (NBER) and CEPR (e-mail: wojciechkopczuk@columbia.edu); Munroe: Department of Economics, Columbia University, 420 West 118th Street, New York, NY 10025 (e-mail: djm2166@ columbia.edu). We are grateful to Chris Mayer, the Paul Milstein Center for Real Estate, and the Real Estate Board of New York for the data. Gilles Duranton, Bill Gentry, Hilary Hoynes, Henrik Kleven, Randy Reback, Maya Rossin-Slater, Anindya Sen, and seminar participants at Columbia and Syracuse Universities, Federal Reserve Board of Governors, Wharton School of Business, New York Fed, University of Toronto, New Economics School, Northwestern University, 2013 IIPF meeting, the 2013 meeting of the CEA, 2014 meeting of the AEA, and 2014 Utah Business Economics Conference provided many helpful suggestions.

${ }^{\dagger}$ Go to http://dx.doi.org/10.1257/pol.20130361 to visit the article page for additional materials and author disclosure statement(s) or to comment in the online discussion forum.
} 
empirics allow for studying the impact of discontinuous incentives on the existence of the market itself.

Our empirical approach relies on variation generated by the discontinuous nature of the taxes imposed in New York and New Jersey, which are levied as a function of the appropriately defined purchase price. A prominent example is the so-called "mansion tax" in New York state (since 1989) and New Jersey (since 2004) that applies to residential transactions of $\$ 1$ million or more. The tax rate is 1 percent and is imposed on the full value of the transaction so that a $\$ 1$ million sale is subject to a $\$ 10,000$ tax liability, while a $\$ 999,999$ transaction is not subject to the tax at all. In New York City, all real estate transactions are also subject to the real property transfer tax (RPTT) and in New Jersey they are subject to the Realty Transfer Fee (RTF) - both of these schedules happen to have (smaller) discontinuities as well, as we discuss in Section I. Hence, all of these taxes create tax "notches" (see Slemrod 2010), while the introduction of the tax in New Jersey also creates a time discontinuity. ${ }^{1}$ Furthermore, the statutory incidence is different for the mansion tax (which is the responsibility of the buyer) than for the New Jersey RTF and New York City RPTT (which are the responsibility of sellers, with the exception of sales of new constructions in New York City). Interestingly, such discontinuities are not uncommon-for example, they are also present in the United Kingdom (Besley, Meads, and Surico 2013; Best and Kleven 2013) and Washington, DC (Slemrod, Weber, and Shan 2012).

Our results allow us to reach three sets of conclusions. First, and perhaps least surprisingly, we find that the tax distorts the price distribution resulting in significant bunching just below $\$ 1$ million. This bunching is evident in the distribution of sales in New York displayed in Figures 1 and 2.2 A similar pattern appears in New Jersey after the introduction of the tax. Figures 3 and 4 demonstrate that the onset of this effect is immediate. The bunching we observe is substantial: our estimates robustly indicate that about $\$ 20,000$ worth of transactions shift to the threshold in response to the $\$ 10,000$ tax. The strength of this effect does not significantly vary with our proxies for tax evasion and we show, using listings data, that a distortion of similar magnitude is already present when properties are first advertised by sellers, which we interpret as inconsistent with tax evasion. We find some evidence that the effect is weaker (but still strong) for newly built properties that sell when already finished, suggesting that real adjustments to the characteristics of a property may be part of the effect. Still, we conclude that real responses do not fully account for the extent of bunching and the tax near the threshold imposes a substantial burden on sellers. Results from smaller discontinuities that shift statutory incidence are consistent with this conclusion.

Second, we build a theoretical framework to illustrate and test for unraveling of the market above the threshold-the possibility that the tax locally destroys trades of matches with remaining positive surplus. Figures 1, 2, and 3 show that the

\footnotetext{
${ }^{1}$ There are also geographic discontinuities that we do not exploit: the RPTT changes at the New York City border, and both RTF and the pre-2004 mansion tax change at the New Jersey-New York border.

${ }^{2}$ Figure 1 corresponds to the whole state, while Figure 2 is for New York City itself. We present the two figures with different binning and overlaying the fit on just one of them in order to present both the visual evidence of the effects and illustrate salient features of the data (round number bunching) that we address in the empirical analysis.
} 


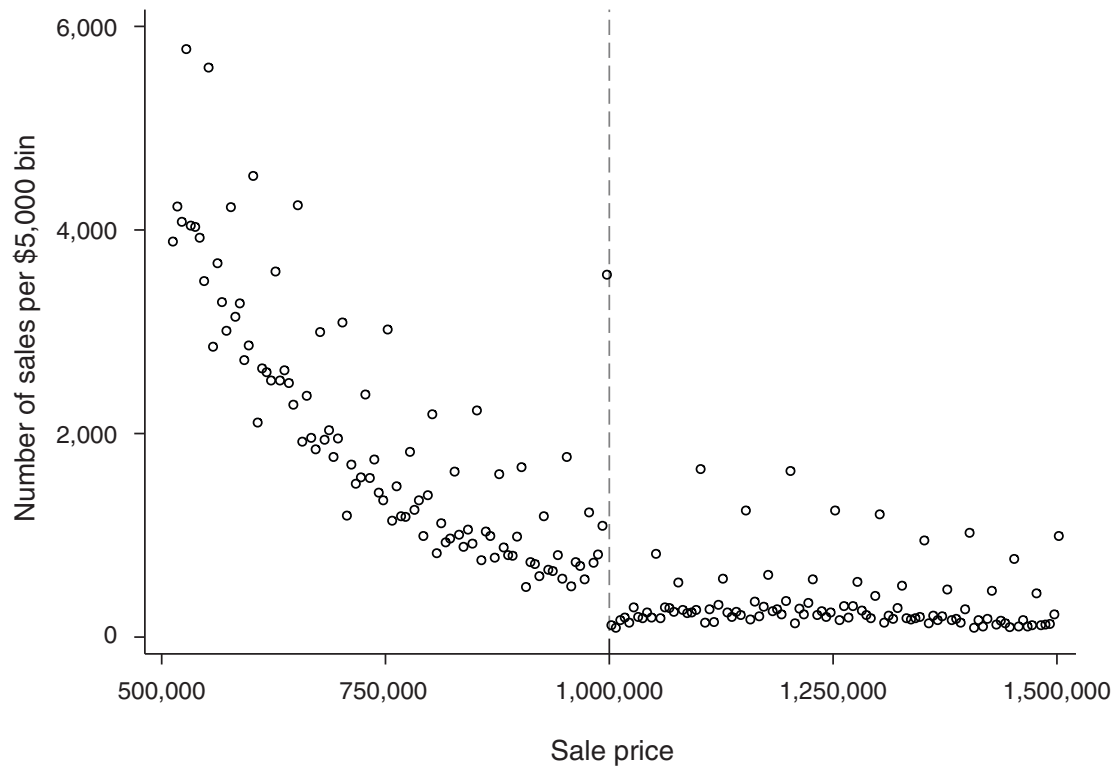

Figure 1. Distribution of Taxable Sales in New York State

Notes: Plot of the number of mansion-tax eligible sales in each $\$ 5,000$ price bin between $\$ 500,000$ and $\$ 1,500,000$.

Source: Data from the New York City Rolling Sales file for 2003-2011 (taxable sales defined as single-unit noncommercial sales of one-, two-, or three-family properties) and from the New York State Office of Real Property Service deeds records for 2002-2006 and 2008-2010 (taxable defined as single-parcel residential sales of one-, two-, or three-family homes).

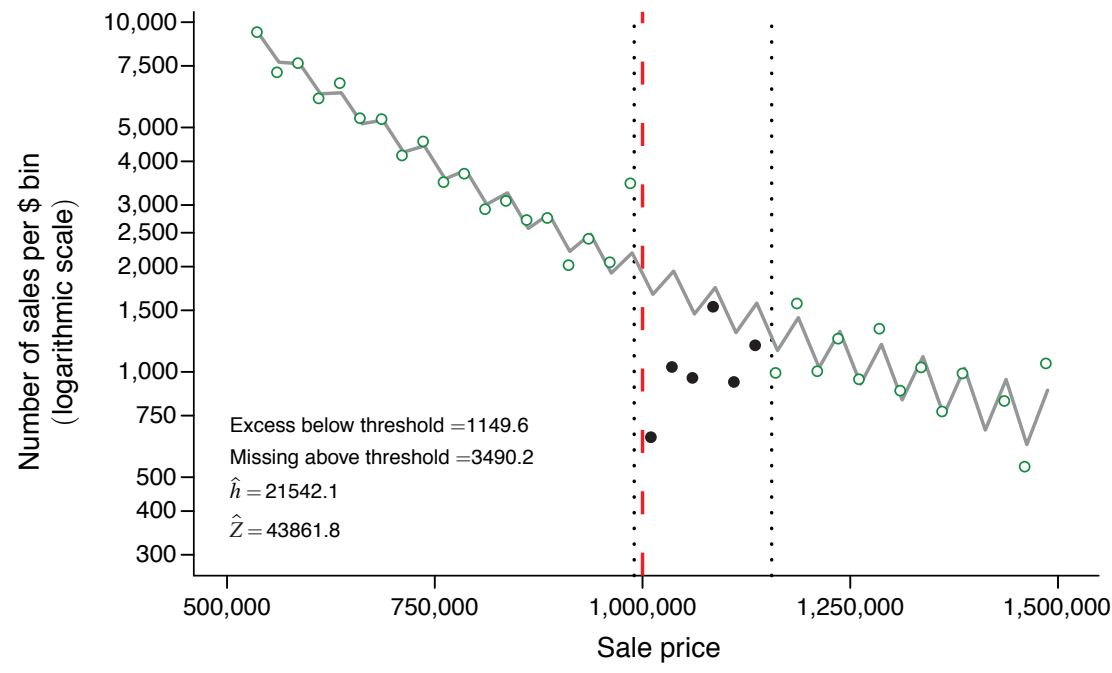

$\circ$ log of sales in $\$ 25 \mathrm{~K}$ bins $\quad$ Omitted from estimation $\quad$ Counterfactual

Figure 2. Distribution of Taxable Sales in NeW York City

Notes: Plot of the number of mansion-tax eligible sales in each $\$ 25,000$ price bin between $\$ 510,000$ and $\$ 1,500,000$. Fit corresponds to the baseline specification in Table 5.

Source: Data from the New York City Rolling Sales file for 2003-2011. 


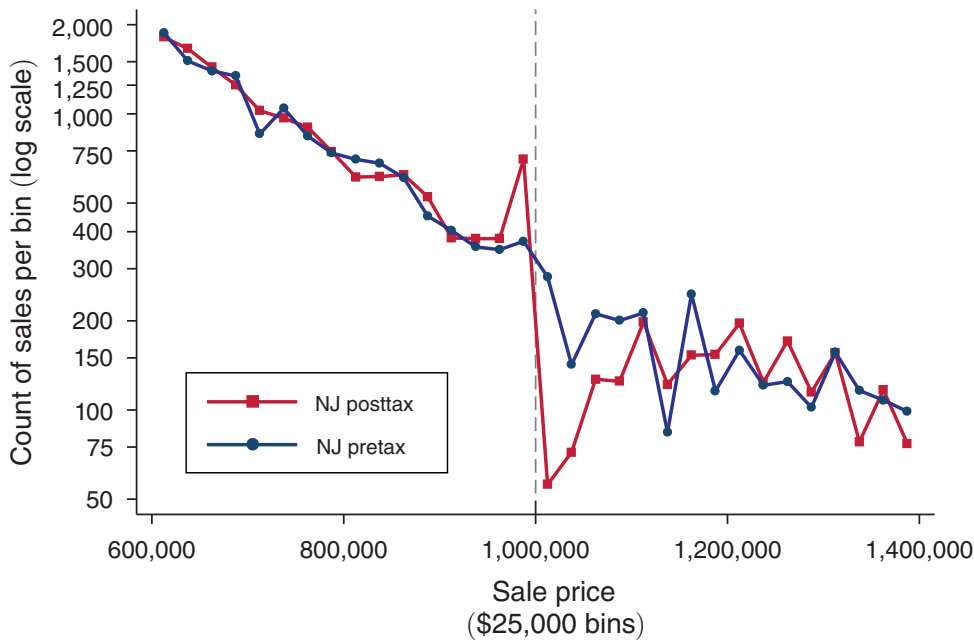

Figure 3. Distribution of New Jersey Sales Pre- and Post-Mansion Tax

Notes: Plot of the number of mansion-tax eligible sales in each $\$ 25,000$ price bin between $\$ 600,000$ and $\$ 1,400,000$ before and after the introduction of the tax. We implement this pre/post comparison as follows. We omit transactions within 90 days of the policy change (to avoid the retiming response) and focus on the following year (October 30, 2004-October 29, 2005). We rescale the period before the tax (May 3, 2003 to May 2, 2004) to account for sales growth over time. Specifically, we construct a counterfactual growth factor by taking the ratio of the count of sales within \$2,500 of each price from May 3, 2002 to May 2, 2003 to the count of sales from November 5, 2000 through November 4, 2001 (omitting sales between November 2001 and May 2002 to mimic the 180-day gap around the introduction of the tax in August 2004).

Source: Data from the New Jersey Treasury SR1A file (taxable defined as any residential sale).

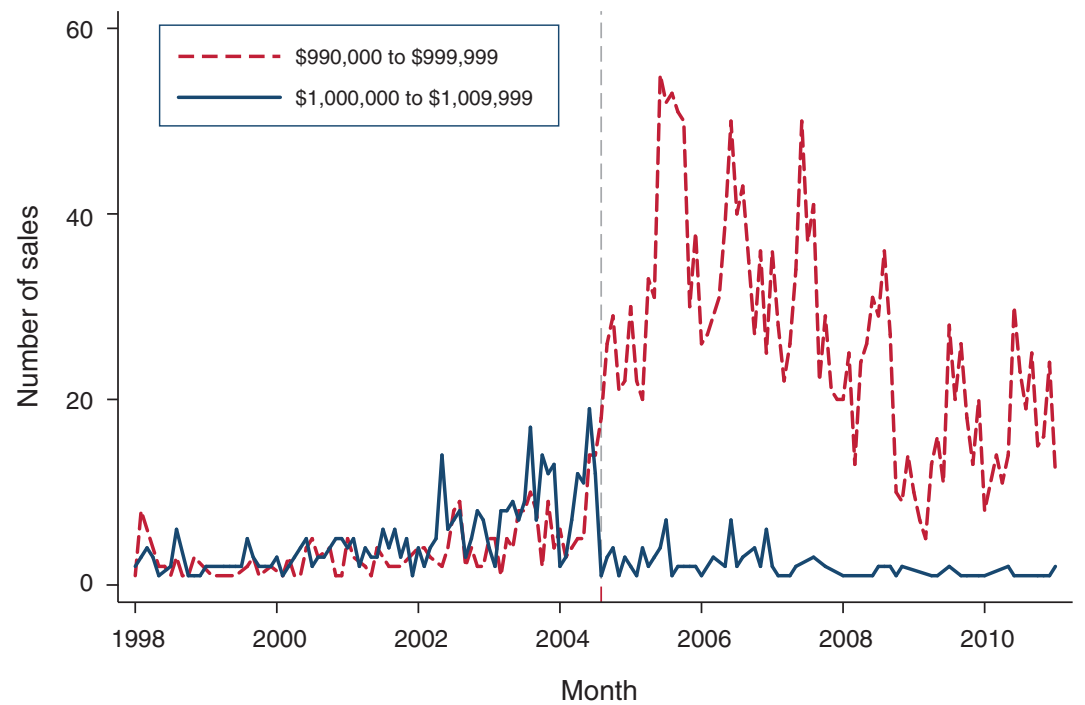

Figure 4. New Jersey Monthly Sales Above $\$ 990,000$

Notes: Total taxable New Jersey sales in given price range by month. Mansion tax introduced in August 2004 (denoted by gray dashed line).

Source: Data from the New Jersey Treasury SR1A file for 1998-2011 (taxable defined as any residential sale). 


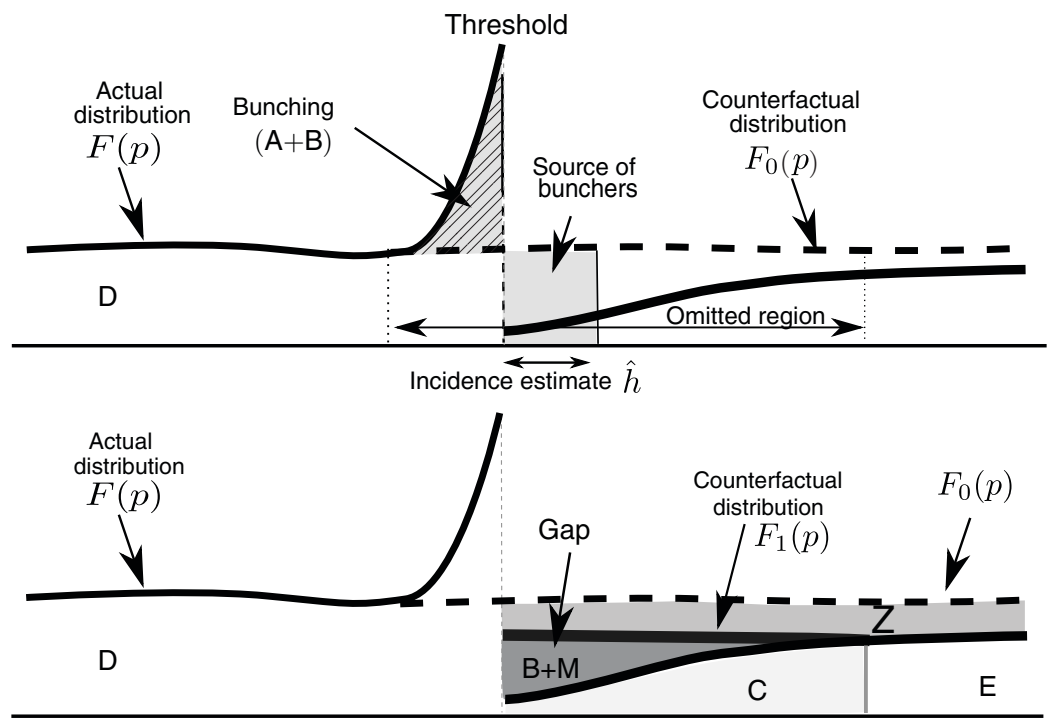

Figure 5. InCIDENCE AND GAP CONCEPTS

distribution of prices features a large gap above the threshold. If all transactions with positive surplus when taxed continue to transact in the presence of the discontinuous tax, the gap is expected to reflect observations shifting from just above the notch (in absence of the tax) to bunch below the threshold. In particular, the gap above the notch is expected not to be bigger than the extent of bunching below. This is a testable prediction. If it fails, it implies that some of the observations are not occurring over and beyond the standard extensive margin response - the phenomenon that we refer to as "unraveling:" transactions with positive surplus that could otherwise occur not far from the notch are not taking place at all. Moreover, we show that the difference between the size of the gap and the extent of bunching is a lower bound for the number of missing transactions. One explanation for such unraveling is that sellers, who face a large burden from these sales, may instead opt out or continue waiting (by foregoing selling altogether or renting, for example), or buyers may prefer to continue searching in order to benefit from locally depressed prices.

The implementation of our test for unraveling is straightforward and illustrated in Figure 5 (that we explain in more detail later in the paper). Conceptually, we estimate bunching at the threshold by constructing the counterfactual distribution based on the data to the left of the threshold and comparing this to the observed bunching at the notch. We estimate the gap by constructing the counterfactual distribution based on the data well to the right of the threshold (i.e., affected by the tax and, thus, accounting for the standard extensive-margin response) and comparing this to the observed gap in sales above the notch. ${ }^{3}$ Intuitively, the after-tax counterfactual used to estimate the size of the gap is, by construction, already net of the standard extensive margin response (matches that have surplus lower than the tax)

\footnotetext{
${ }^{3}$ In practice, we usually simply allow for a shift in the distribution at the threshold to parsimoniously capture the two different counterfactual distributions. We also report results that rely on separate estimation on both sides.
} 
and thus the gap only reflects sales that have shifted to the threshold or matches with continued positive surplus in the presence of the tax that do not sell. We argue that these missing transactions would have sold if they were far from the threshold, but are discouraged by the incentives presented by the notch to continue searching.

We indeed find that more transactions are missing from the gap than we can observe bunching at the threshold, indicating that the market unravels locally. This effect is large: our baseline estimates indicate that over $\$ 40,000$ worth of transactions (i.e., equivalent to the mass of transactions that would sell between $\$ 1,000,000$ to $\$ 1,040,000$ in absence of the tax) that would still yield positive surplus even with the tax do not take place. This corresponds to 2,800 missing transactions in New York City, out of 380,000 that occurred over the whole period. Hence, by our estimates, this 1 percent tax, applying at a relatively large threshold, managed to eliminate 0.7 percent of transactions due to the unraveling effect. To reiterate, our interpretation of this response is conceptually different from the standard demand response that is due to higher taxes discouraging transactions with low surplus: unraveling corresponds to eliminating transactions with positive surplus in the presence of the tax. This additional extensive-margin response indicates that the substantial friction introduced by the transaction tax hampers functioning of the market in some region above the threshold. Given our sources of variation, estimating the standard response would require making strong assumptions about comparability of distributions with and without taxes, and we do not pursue it in this paper.

Recognition and empirical identification of the type of extensive margin response that we focus on is a novel contribution. There are, of course, known examples of frictions eliminating particular markets-most prominently, asymmetric information affecting the existence of insurance markets. We find that the notched design of the tax can destroy a market for housing with values close to the notch, which has not been previously recognized. We argue that such a response is present because of the search frictions in the housing market and may apply in any situation where search is present and the population affected by distortionary incentives is not fixed. ${ }^{4}$

Unraveling has important implications for empirical work that relies on notches. Much of this literature focuses on contexts where only the intensive margin is of interest, such as income taxation, and hence this point has not been recognized before. In particular, our results indicate that in situations where the volume of taxable units is endogenous (as in housing, but perhaps not under the income tax far from the filing threshold where nonfiling may be negligible), exits around kinks/notches cannot be assumed to be the standard extensive margin and, hence, such responses cannot be generalized as reflecting the effect on behavior elsewhere. One must be careful about separating unraveling from the standard effect-response to the tax in general may differ substantially from behavior close to the notch. ${ }^{5}$ Similarly, estimation of the extent of optimization frictions as in Kleven and Waseem (2013) relies on measuring the size of the gap, which would partially reflect unraveling if

\footnotetext{
${ }^{4}$ More speculatively, we briefly comment in Section V on figures from our online Appendix that indicate possible changes in patterns of behavior during the search process.

${ }^{5}$ In particular, extensive margin responses in other papers exploiting discontinuities in transaction taxes (Slemrod, Weber, and Shan 2012; Best and Kleven 2013; Besley, Meads, and Surico 2013) are subject to this critique.
} 
present. Moreover, the possibility of unraveling complicates estimation of a general (i.e., not specific to the notch) intensive-margin response to a notched policy, such as the approach described by Kleven and Waseem (2013). We demonstrate how a general response of price to the transfer tax, as determined by the relative bargaining power of buyers and sellers, could be estimated by adjusting bunching by the size of the gap. This procedure eliminates the part of the response that is driven by the discrete impact of the notch, leaving only the effect of a continuous tax. However, such an estimate will be biased (perhaps substantially) in the presence of unraveling.

Our third set of conclusions finds evidence indicating that the impact of the tax is not limited to the proximity of the threshold, but extends much further. Both price reductions while properties are listed and discounts (the difference between final advertised and sale price) increase permanently above the threshold, indicating that the search and matching process is affected everywhere by the tax. Furthermore, we find that in the presence of the tax listing prices are a weaker signal of the final sale price of the property. Relying on our theoretical arguments, we interpret this greater dispersion of sale price conditional on asking price as corresponding to increased deviation from the efficiency-maximizing matching equilibrium and conclude that a general transaction tax increases inefficiency in the search process.

A small literature focuses on the effect of transfer taxes on the functioning of the real estate market (Benjamin, Coulson, and Yang 1993; Van Ommeren and Van Leuvensteijn 2005; Dachis, Duranton, and Turner 2012). Contemporaneously, three other papers (Slemrod, Weber, and Shan 2012; Best and Kleven 2013; Besley, Meads, and Surico 2013) look at similar distortions to the distribution of final prices (but not listings) in the United Kingdom and Washington, DC. These studies focus on the standard extensive margin response (the general effect on sales) to policy changes, rather than incidence, listings, and search frictions as we do. We are also unique in showing evidence of unraveling - that the extensive margin effect of the tax goes beyond eliminating transactions with negative net-of-tax surplus. Beyond offering the first, to our knowledge, evidence of this type of an effect, these results cast doubt on generalizing from responses around notches and kinks (where market can unravel) to elsewhere (where only standard extensive margin response should be present) in the presence of matching frictions.

Another strand of literature to which we contribute analyzes the search and matching process in the real estate market. Several studies focus on the role of listing prices and bargaining in determining the final sale outcome (c.f. Han and Strange 2012, 2014; Merlo and Ortalo-Magne 2004; Haurin et al. 2010), while a few apply more general search models to real estate data (c.f. Carrillo 2012; Genesove and Han 2012). However, these studies do not explicitly identify the effect of transaction costs, such as transfer taxes, on outcomes. A related line of study focuses on the role of real estate agents, attempting to unbundle the effect of cost from information provision (Levitt and Syverson 2008; Jia and Pathak 2010; Bernheim and Meer 2013). Finally, a number of empirical papers incorporate information available in real estate listings data to the study of seller behavior in the housing market (Genesove and Mayer 2001; Carrillo and Pope 2012).

Our paper is also related to the broader body of work on behavioral responses to taxation. As in the research on responses to income taxation, we 
Table 1 -Real Estate Transfer Tax Schedules

\begin{tabular}{lccccc}
\hline \hline Tax & Threshold $(\$)$ & $\begin{array}{c}\text { Rate } \\
\text { below }\end{array}$ & $\begin{array}{c}\text { Rate } \\
\text { above }\end{array}$ & Jump & $\begin{array}{c}\text { Statutory } \\
\text { incidence }\end{array}$ \\
\hline Mansion Tax (NY \& NJ) & $\$ 1,000,000$ & $0 \%$ & $1 \%$ & $\$ 10,000$ & Buyer $^{\text {N }}$ \\
RPTT (NYC, residential) & $\$ 500,000$ & $1 \%$ & $1.425 \%$ & $\$ 2,125$ & Seller $^{\text {a }}$ \\
RPTT (NYC, commercial) & $\$ 500,000$ & $1.425 \%$ & $2.625 \%$ & $\$ 6,000$ & Seller $^{\text {Seller }}$ \\
RTF (NJ) & $\$ 350,000$ & $0.78 \% \mathrm{~b}$ & $0.96 \%$ & $\$ 630$ & Sel \\
\hline
\end{tabular}

\footnotetext{
${ }^{\mathrm{a}}$ Buyer remits tax if the sale is of newly developed property (otherwise Seller remits).

${ }^{b}$ NJ RTF schedule features nonlinear tax schedule below $\$ 350,000$, all of which changes when the sale price crosses the notch; 0.78 percent and 0.96 percent are simply the marginal rates faced above and below the notch.
}

are interested in separating real, timing, avoidance, and evasion responses (Slemrod 1990; Saez, Slemrod, and Giertz 2012). Contrary to that strand of work, our context requires considering both sides of the market. There has been a recent revival of interest in estimating the incidence of specific taxes/transfers (e.g., Doyle Jr. and Samphantharak 2008; Mishra, Subramanian, and Topalova 2008; Hastings and Washington 2010; Marion and Muehlegger 2011). Real estate tax is more complicated due to non-homogeneity of goods traded, and the closest analogue is work on incidence of income/payroll taxes or credits (Rothstein 2010; Saez, Matsaganis, and Tsakloglou 2011).

The structure of the paper is as follows. In the next two sections, we discuss the institutional and policy context and our data. In Section III, we present our theoretical framework. We start by introducing a bargaining framework that illustrates the effect of the tax for a particular match, followed by discussion of frictionless equilibrium and predictions regarding the effect of the tax on the price distribution. We then derive simple testable implications of the presence of frictions to matching. In Section IV, we present empirical results about the distribution of prices, both graphical evidence and local incidence estimates for various types of taxes, relying on price and listings data. We also show evidence for various subsamples in order to shed a light on the role of evasion and real adjustments. In Section V, we focus on distortions to the matching process near the threshold and present our results about the extent of unraveling. In Section VI, we demonstrate the global effect of the tax on discounts and informational content of listings. Conclusions are in the final section.

\section{Policy}

Real estate transfer taxes are common across the United States. These taxes are applied to the sale price of real property, and range from as low as no tax in Texas to 2 percent in Delaware. In New York and New Jersey, the tax rates change discontinuously with total consideration, creating corresponding notches in total tax liability. Table 1 contains details of the relevant tax schedules. One notch arising in both states is due to the mansion tax: a 1 percent tax on the total consideration for homes costing $\$ 1,000,000$ or more. Under the mansion taxes of both New York and New Jersey buyers' total tax liability jumps by $\$ 10,000$ when the sales price moves 
from $\$ 999,999$ (where the tax does not apply) to $\$ 1,000,000$ (where the tax comes into effect). In New Jersey, the mansion tax was introduced on August 1, 2004, and covers all residential real estate transactions. In New York state, the mansion tax was introduced in 1989 and applies to the sale of individual co-op and condo units, and one-, two-, and three-family homes, with few exceptions. ${ }^{6}$

Real estate sales in New York City and New Jersey are subject to additional taxes with discontinuous average rates. In New York City, the Real Property Transfer Tax (RPTT) applies to residential sales (as defined for the New York mansion tax) with a rate of 1 percent if the total consideration is $\$ 500,000$ or less, and 1.425 percent above $\$ 500,000$. Commercial sales are also subject to the RPTT at a rate of 1.425 percent below $\$ 500,000$ and 2.625 percent above. Unlike the mansion tax the statutory incidence of the RPTT falls on the seller by law, however it is customary for the buyer to pay the tax when purchasing directly from a sponsor (i.e., purchasing a newly developed condo or a newly offered co-op). Thus, the RPTT is a unique tax in that there is variation in the statutory incidence.

Residential sales in New Jersey are subject to the Realty Transfer Fee. This transfer fee (or tax) has a nonlinear schedule (see Table 1) that shifts when total consideration is greater than $\$ 350,000$. The marginal tax rate for consideration above $\$ 200,000$ is 0.78 percent if the total price is less than or equal to $\$ 350,000$, while this tax rate jumps to 0.96 percent when the total price is greater than $\$ 350,000$. Moving from a price of $\$ 350,000$ to $\$ 350,001$ increases the buyer's tax liability by $\$ 630$.

\section{Data}

We study administrative records on real estate transactions in New York State and New Jersey as well as historical real estate listings in New York City. Sales records, which cover the universe of recorded real estate transactions in the given geography and time period, come from three sources: the New York City Department of Finance's (NYCDOF) Annualized Rolling Sales files for 2003-2011 (covering all of New York City), real property transfer reports compiled by the New York state Office of Real Property Services (NYSORPS) for 2002-2006 and 2008-2010 (all of New York State, excluding the five counties of New York City), and SR1A property transfer forms collected in the New Jersey Treasury's SR1A file for 1996-2011 (all of New Jersey). These records contain details of each transaction, including the date of sale, the total consideration paid by the buyer, the address of the property, the property type (e.g., one-, two-, or three-family home, residential co-op or condo, etc.), the year of construction of the building (in NYC and NJ) or whether the property is newly constructed (in New York State), and whether the sale is arms-length (NYSORPS only).7 We also use deeds records for 1996-2008 for New York City

\footnotetext{
${ }^{6}$ Exceptions are as follows. If a residential unit is partially used for commerce, only the residential share of the total consideration is subject to the tax (although the entire consideration is still used to determine if the tax applies). Similarly, multiple parcels sold in the same transaction are taxed as one unit unless the parcels are evidently not used in conjunction with one another. Vacant lots are exempt from the mansion tax, and, finally, any personal effects sold with the home are deducted from the total consideration for tax purposes (but are subject to state sales taxes).

${ }^{7}$ This definition excludes sales between current or former relatives, between related companies or partners in business, sales where one of the buyers is also a seller, or sales with "other unusual factors affecting sale price." See online Appendix B for more details.
} 
collected by an anonymous private data provider from the county records, which indicate whether the buyer relied on a mortgage (see online Appendix B for more information about data sources). 8

We identify sales that are subject to each of the transfer taxes. Misclassification in taxable status, if any, will introduce a bias against finding effects, however it is unlikely to be substantial: our information comes from administrative records that contain sufficient information to classify, even though an explicit taxability flag is not provided. In New Jersey, we consider all "residential" sales to be taxable (mansion tax and Transfer Fee). For New York state, we define all single-parcel residential sales of one-, two-, or three-family homes, condos, and seasonal properties as subject to the mansion tax. Finally, in New York City we define all single-unit (noncommercial) sales of one-, two-, or three-family homes, co-ops, and condos as taxable. 9

We match the Rolling Sales data for Manhattan to a subset of historical real estate listings in order to get a broader picture of the effect of the tax on the real-estate search process. Our listing data comes from the Real Estate Board of New York's (REBNY) electronic listing service and covers all closed or off-market listings between 2003 and 2010. REBNY is a trade association of about 300 realty firms operating in New York City and represents a substantial share of listings in Manhattan and Brooklyn. Members are required to post all listings and updates to the electronic listing service. We limit attention to the more complete Manhattan listings, which account for approximately 45 percent of Manhattan sales in the Rolling Sales files.

From the REBNY listing service we observe details of all (REBNY-listed) closed or off-market listings since 2003. These data include initial asking price and date of each listing, all subsequent price updates, and the date the property sells or is taken off the market. To acquire the final sale price, we match these listings by precise address (including apartment number) and/or tax lot to the NYCDOF data for Manhattan. We obtain approximately a 90 percent match rate for listings identified as "closed" in the REBNY data. 10

Table 2 presents descriptive statistics from the three sources of sales data. Overall, we have records for 3,256,597 taxable sales (with nonzero sale price) spanning 1996-2011. The distribution is skewed: mean sale price is higher than the median. Unsurprisingly, prices are highest in New York City. Although median (and mean) sale price is well below the $\$ 1,000,000$ threshold of the mansion tax, there are still several thousand sales per geography within $\$ 50,000$ of the mansion-tax cutoff. Table 3 presents the count of taxable residential sales and median prices over time for the three regions. The growth of housing sales and prices throughout the early 2000s is evident here, as is the subsequent drop in total sales and median price at the onset of the recession in 2007-2008.

\footnotetext{
${ }^{8}$ We are grateful to Chris Mayer and the Paul Milstein Center for Real Estate for access to this data.

${ }^{9}$ While multi-parcel sales in New York state are typically subject to the mansion tax, such a sale may be split for tax purposes if structures on adjacent parcels are not used in conjunction with or clearly related to one another. Since we cannot identify such cases in the New York City and New York state data, we err on the side of caution and exclude all multi-parcel and partially-commercial sales from taxable status.

${ }^{10}$ The match-rate is continuous across the tax thresholds. See online Appendix B for details on the matching process.
} 
Table 2-Sample Statistics for Taxable Sales

\begin{tabular}{lcrr}
\hline \hline & NYC & \multicolumn{1}{c}{ NYS } & \multicolumn{1}{c}{ NJ } \\
& $(2003-2011)$ & $(2002-2010)$ & $(1996-2011)$ \\
\hline Number of sales & 380,629 & $1,172,708$ & $1,703,260$ \\
Sales $\in(\$ 950 \mathrm{k}, \$ 1.05 \mathrm{M})$ & 7,932 & 6,242 & 7,556 \\
Median price & 405,600 & 159,900 & 200,000 \\
Mean price & 660,719 & 258,363 & 262,122 \\
\hline
\end{tabular}

Source: New York City data is from the Department of Finance Rolling Sales file for 2003-2011 (taxable sales defined as single-unit, noncommercial sales of one-, two-, or three-family homes, coops, and condos). Data for New York State from Office of Real Property Service deeds records for 2002-2006 and 2008-2010 (taxable defined as all single-parcel residential sales of one-, two-, or three-family homes). Data for New Jersey from the State Treasury SR1A file for 1996-2011 (taxable defined as any residential sale).

Table 3-Median Price of Taxable Sales Over Time

\begin{tabular}{|c|c|c|c|c|c|c|}
\hline \multirow[b]{2}{*}{ Year } & \multicolumn{2}{|c|}{ NYC } & \multicolumn{2}{|c|}{ NYS } & \multicolumn{2}{|c|}{ NJ } \\
\hline & $n$ & Price & $n$ & Price & $n$ & Price \\
\hline 1996 & & - & - & - & 111,759 & 127,000 \\
\hline 1997 & - & - & - & - & 115,470 & 130,000 \\
\hline 1998 & - & - & - & - & 131,485 & 137,500 \\
\hline 1999 & - & - & - & - & 139,167 & 143,000 \\
\hline 2000 & - & - & - & - & 136,891 & 151,000 \\
\hline 2001 & - & - & - & - & 136,733 & 169,000 \\
\hline 2002 & - & - & 163,491 & 132,000 & 145,718 & 197,000 \\
\hline 2003 & 47,679 & 293,000 & 167,709 & 149,500 & 148,906 & 235,000 \\
\hline 2004 & 53,342 & 340,000 & 175,766 & 165,000 & 159,220 & 270,155 \\
\hline 2005 & 52,310 & 395,460 & 175,873 & 184,640 & 155,340 & 315,000 \\
\hline 2006 & 47,973 & 445,000 & 152,220 & 170,000 & 127,630 & 327,000 \\
\hline 2007 & 48,552 & 480,000 & 5,934 & 287,000 & 108,790 & 321,050 \\
\hline 2008 & 40,354 & 475,000 & 117,000 & 162,500 & 86,151 & 288,000 \\
\hline 2009 & 31,368 & 420,000 & 110,408 & 155,500 & 83,407 & 257,500 \\
\hline 2010 & 27,132 & 463,000 & 104,307 & 160,666 & 80,944 & 250,000 \\
\hline 2011 & 31,919 & 456,000 & . & . & 28,766 & 250,000 \\
\hline
\end{tabular}

Notes: New York City data is from the Department of Finance Rolling Sales file for 2003-2011 (taxable sales defined as single-unit, noncommercial sales of one-, two-, or three-family homes, co-ops, and condos). Data for New York State from the Office of Real Property Services deeds records for 2002-2006 and 2008-2010 (taxable defined as all single-parcel residential sales of one-, two-, or three-family homes). New York State observations in 2007 are from sales made in 2007, but recorded in 2008-2011 and omits sales recorded in 2007. Data for New Jersey from the State Treasury SR1A file for 1996-2011 (taxable defined as any residential sale).

Table 4 presents statistics for the matched REBNY listings data. The sales covered by REBNY have much higher prices, on average, than the general NYC rolling sales data ( $\$ 1.24$ million versus $\$ 658,000)$. This is due to the REBNY data only covering sales in Manhattan, which is considerably more expensive than the outer boroughs. About 64 percent of the homes in our sample end up closing (rather than being taken off the market). At the same time, 8 percent of listings do not close but have a corresponding sale in the rolling sales data, which we interpret as corresponding to either direct sales by owner or sales with a non-REBNY agent. Homes 
TABle 4-REBNY Listings SAmple Statistics

\begin{tabular}{|c|c|c|c|c|c|c|c|}
\hline & & & All & ngs & & & \\
\hline & Sold & $\begin{array}{c}\text { Matched, } \\
\text { but not } \\
\text { closed }\end{array}$ & $\begin{array}{l}\text { Days } \\
\text { on } \\
\text { market }\end{array}$ & $\begin{array}{c}\text { Initial } \\
\text { asking } \\
\text { price }\end{array}$ & $\begin{array}{l}\text { Final } \\
\text { asking } \\
\text { price }\end{array}$ & $\begin{array}{c}\text { Discount } \\
\text { (first to } \\
\text { final) }\end{array}$ & \\
\hline Mean & 0.671 & 0.103 & 197.859 & $1,604,547$ & $1,602,670$ & 0.019 & \\
\hline Median & 1.000 & 0.000 & 110.000 & 899,000 & 875,000 & 0.000 & \\
\hline$n$ & 71,875 & 71,875 & 67,550 & 71,875 & 71,875 & 71,875 & \\
\hline & & & losed and $\mathrm{r}$ & ched listing & & & \\
\hline & $\begin{array}{c}\text { Days } \\
\text { on } \\
\text { market }\end{array}$ & $\begin{array}{c}\text { Initial } \\
\text { asking } \\
\text { price }\end{array}$ & $\begin{array}{c}\text { Final } \\
\text { asking } \\
\text { price }\end{array}$ & $\begin{array}{l}\text { Sale } \\
\text { price }\end{array}$ & $\begin{array}{l}\text { Discount } \\
\text { (first to } \\
\text { final) }\end{array}$ & $\begin{array}{c}\text { Discount } \\
\text { (first to } \\
\text { sale) }\end{array}$ & $\begin{array}{c}\text { Discount } \\
\text { (final to } \\
\text { sale) }\end{array}$ \\
\hline Mean & 146.107 & $1,384,028$ & $1,435,747$ & $1,241,209$ & 0.032 & 0.059 & 0.028 \\
\hline Median & 80.000 & 825,000 & 799,000 & 784,052 & 0.000 & 0.043 & 0.023 \\
\hline$n$ & 40,680 & 44,320 & 44,320 & 44,193 & 43,506 & 43,309 & 43,309 \\
\hline
\end{tabular}

Notes: Sold is an indicator equal to one if the final status of the listing is "Closed." Days on the market is calculated as the number of days between the initial active listing and the final status of "in contract" (if the property sells with REBNY) or "permanently off market" (otherwise). Initial asking price is the asking price on the listing when first active; final asking price is the price listed immediately prior to the listing being "in contract" or being taken off the market (if unsold). Sale price is the price reported in the NYC DOF data and is available only for REBNY listings that have a match in the DOF data (sale price of 0 is considered missing). Discount is defined as $1-\frac{\text { final price }}{\text { first price }}$ and is windsorized at the first and ninety-ninth percentiles. A total of 5,940 listings have invalid listing and off-market dates (missing or obviously misreported), and are omitted from days on market calculations. "Matched, but not closed" is an indicator that a listing has a match in the NYC DOF data, but is never reported as "Closed" by the REBNY agent.

Source: Data from the Real Estate Board of New York's listing service; represents all REBNY listings in Manhattan between 2003 and 2010 that are closed or off market.

that do not close spend more time on the market (200.5 days versus 146 for sold properties). These statistics suggest that search frictions are nonnegligible in the housing market — the process of finding a buyer for a home is lengthy and sellers are often unable to find a match. There also appears to be bargaining between buyers and sellers: for properties that close and are matched to the rolling sales data, the average discount between the initial asking price and the sale price ( $\left.\frac{\text { initial }- \text { sale }}{\text { initial }}\right)$ is 5.9 percent: 3.2 percent discount from initial asking to final asking price and a 2.8 percent discount from final asking price to sale price. However, the median listing in our sample has no price updates between the initial and final asking prices.

\section{Theoretical Framework}

To interpret our empirical findings, we present a simple model of real-estate transactions. We first discuss implications of taxation in a bargaining framework given a match between a buyer and a seller. We then characterize the equilibrium and its responsiveness to taxation absent search frictions. The equilibrium in this situation corresponds to assortative matching. We follow with a discussion of how the price distribution might respond when individuals search and need not transact conditional on matching. Finally, we elaborate on how the equilibrium price dispersion (which is present when there are matching frictions) may respond to taxation, and 


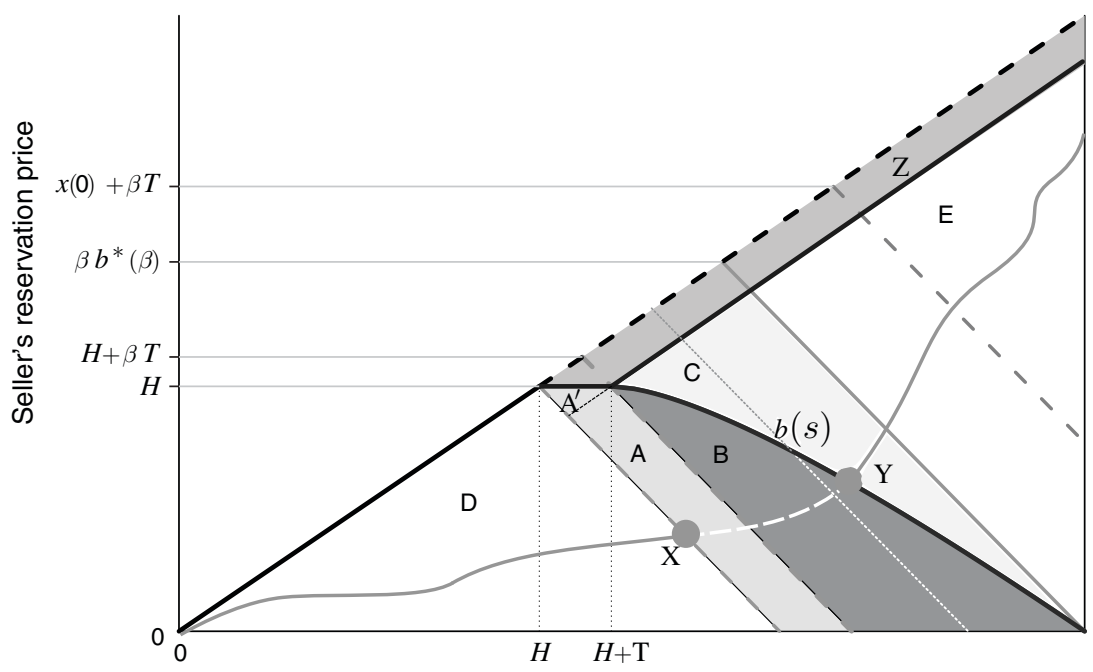

Buyer's reservation value

Figure 6. Bunching at the Notch and Efficient Allocation

how these effects can be empirically characterized by relying on observable information (including listings data).

\section{A. Bargaining}

We start with a bargaining model that clarifies the nature of distortions to the price distribution around the notch and relates tax incidence observed at the notch to the bargaining power that determines incidence elsewhere. For now, we abstract from equilibrium considerations and instead characterize pricing behavior given a match. This is a building block of the equilibrium analysis that we come back to below. The Nash bargaining model itself is formally presented in the Appendix A. Here, we introduce the intuition underlying the model and illustrate key results on Figure 6. The figure corresponds to a lump-sum tax, but the main insights apply as well to the proportional tax that we discuss in more details in the Appendix.

We assume that transaction prices are determined by Nash bargaining between the buyer and seller. Consider a single match $(b, s)$ between a buyer with a reservation value of $b$ and a seller with reservation value $s$. Given the price that a buyer and a seller negotiate, $p$, and a lump-sum tax $T$ imposed on the buyer (as in the case of the mansion tax), the parties end up with surpluses of $S^{B}=b-T-p$ and $S^{S}=p-s$, respectively. We assume Nash bargaining with seller's weight $\beta$ so that the price maximizes $\beta \ln (p-s)+(1-\beta) \ln (b-T-p)$ and is, thus, set to $p(b, s)-\beta T$, where $p(b, s) \equiv \beta b+(1-\beta) s$ is the price absent taxes. Consequently, the surplus of each side is equal to $S^{B}=(1-\beta)(b-T-s)$ and $S^{S}=\beta(b-T-s)$, which implies that the parameter $\beta$ determines how the total surplus $b-T-s$ is split between the two parties. 
Necessarily, the incidence of the tax is determined by the seller's relative bargaining power, $\beta$, as well. Although it follows automatically from this framework, it is worth highlighting that the party with lower bargaining power bears a lower share of the tax. This party has a lower claim to the surplus in the first place and, symmetrically, experiences a lower reduction in surplus when the tax is imposed. At the extreme, when $\beta=0$ or $\beta=1$, one of the parties has no bargaining power and no surplus, and thus is completely inelastic so that it cannot bear any burden of the tax.

Transaction taxes may also discourage sales. Transactions take place when the surplus is nonnegative $(b-T-s \geq 0)$. All matches $(b, s)$ that satisfy $\beta b+(1-\beta) s=p$, for some $p$, sell at exactly the same price (equal to $p-\beta T$ ) or do not sell at all if total surplus is negative. By reducing the surplus, the uniform lump-sum levy discourages some sales (note that this is the "standard" extensive margin response; we discuss unraveling in Section IIIC).

However, the lump-sum tax does not lead to re-ranking of transactions. All prices simply adjust by $\beta T$, so that transactions that were occurring at the same price absent the tax continue to sell at equal (although different from the original) prices. This lack of re-ranking is not general: it does not survive considering proportional rather than lump-sum taxation, but it simplifies the following discussion and provides a natural benchmark (and, as discussed in the Appendix, the key qualitative results generalize to the proportional tax case).

We illustrate our formal results regarding the price and sales responses to the tax graphically on Figure 6. The figure shows reservation values of buyers and sellers on the two axes, and also allows for tracing prices. The contract line (the relationship between prices of buyers and sellers) in absence of the tax requires that the prices of buyers and sellers have to be the same: $p^{B}=p^{S}$; while in the presence of the tax above the notch it is given by $p^{B}=p^{S}+T \cdot\left(p^{S} \geq H\right)$, where $H$ is the notch $(H=\$ 1,000,000$ for the mansion tax $)$. The solid black line represents this pricing/budget constraint below the notch, the dashed black line represents the no-tax situation above the notch, and the solid line above the notch represents the contract line in the presence of the tax. The light diagonal line and other lines parallel to it show the locus of matches with the same sale price in absence of the tax-i.e., a constant value of $p(b, s)$ (corresponding to the intersection of the given parallel line with the black no-tax contract line). In the presence of the lump-sum tax all matches on any of these lines sell at the same price, given by $p(b, s)-\beta T$, which corresponds to a point where a given constant price line intersects with the contract line. Transactions in the gray shaded area, marked "Z," have positive surplus and would sell without the tax, but they do not sell when the tax is present because the net-of-tax surplus turns negative. Matches in this region reflect the standard extensive margin response.

Price adjustments are affected by the presence of the notch, resulting in some transactions moving from above to just below the notch, and can be broken-down into four cases that depend on the initial (absent-tax) price. Case 1 consists of transactions that originally occur below the price of $H$ and are not affected by the tax (buyer-seller matches in region "D"). Case 2 consists of transactions that, in absence of the tax, sell at a price between $H$ and $H+\beta T$ and would sell below $H$ if the tax 
was uniform (i.e., not notched), but in the presence of the notch occur there. These transactions are illustrated in Figure 6 by the area marked "A" that is bounded by the $p(b, s)$ schedules corresponding to $p(b, s)=H$ and $p(b, s)=H+\beta T$. Given the assumption of maximizing the Nash-bargaining objective function, transactions that originally sell at a higher price than $H+\beta T$ may sell at the notch depending on whether total surplus at the notch or with the tax is higher. We show that for some intermediate range of original (absent-tax) prices above the threshold (Case 3), some transactions will bunch at the notch (region "B"), while others will sell at a new price above the notch (region " $C$ "), depending on the relative size of the seller's and buyer's reservation values for the property. However, when the original price is high enough (greater than some finite pretax price corresponding to the solid diagonal line) no transaction will bunch, constituting our final case (region "E"). In the Appendix, we establish that the qualitative characterization of the effect of taxation on prices described by Figure 6 is general.

The formal model delivers an additional result that is not a priori obvious: there exists a pretax price above which the presence of the notch does not affect any transactions. Firstly, for any $\beta$ there exists a pretax price above which transactions are not affected by the notch-this boundary is determined by considering matches involving a seller with reservation value of zero. Furthermore, and less intuitively, there exists a single finite bound for such maximum pretax prices above which transactions do not bunch that applies uniformly for any value of $\beta$. In the lump-sum tax case, the tight bound (applying as $\beta \rightarrow 0$ ) is the solution to $\ln (H)-\ln (p)-\frac{H-T}{p}+1=0$ and corresponds to $p \approx \$ 1,144,717$ when $H=\$ 1,000,000$ and $T=\$ 10,000$. In the case of the proportional tax, the bound solves $\ln (H)-\ln (p)-\frac{H-p \ln (1+t)}{p}+1=0$ (where $t$ is the marginal tax rate, 1 percent in the case of mansion tax) corresponding to $p \approx \$ 1,155,422$. While this precise characterization is the consequence of functional form assumptions in the case of Nash bargaining, it does provide a theoretical justification for the assumption that we make in our empirical analysis that only matches in some finite omitted region around the notch might bunch. In our empirical analysis, we use this theoretical bound for defining the omitted region in our baseline specification (but of course we explore the sensitivity to this choice).

\section{B. Equilibrium}

The framework that we have introduced so far focuses on price determination given a match between a buyer and seller. This is a component of the equilibrium description-given matches that lead to sales, we assume Nash bargaining as the approach for determining the price. The missing component of the model is a description of how matches form. Providing a complete search framework is beyond the scope of this paper and, in fact, we are not aware of a framework in the literature that would incorporate a two-sided search in the real estate context (Carrillo 2012, makes a step in this direction by setting up, but not explicitly solving, a model of this kind). We make two arguments that we then investigate empirically. First, we consider what the distribution of prices reveals about the distribution of the underlying matches 
and efficiency of the equilibrium. Second, we consider which of the matches are likely to be "stable" in the presence of the tax.

The simplest way to introduce equilibrium consideration in this framework is to assume random matching followed by very large frictions (search costs) preventing both parties from further search so that, conditional on a match, the only decision to make is whether to transact. Under this assumption, there is a matching technology $M(b, s)$ that results in some (smooth) distribution of matches over $(b, s)$, and Figure 6 reflects which of those matches correspond to transactions.

An alternative is to consider a situation with no search frictions. Suppose that we have an equal number of buyers and sellers. Absent taxation, the overall surplus from a match in our Nash bargaining model is strictly supermodular (it is given by $\ln (b-s)+$ constant $)$. Hence, the equilibrium and, simultaneously, the efficient allocation that maximizes the overall surplus involves positive assortative matching. In the presence of taxation, the surplus for transactions not subject to the tax and not at the threshold remains $\ln (b-s)+$ constant, while the surplus for transactions subject to the tax is $\ln (b-s-T)+$ constant (which is, naturally, also supermodular). Hence, within each of these groups maximization of the overall surplus involves assortative matching.

The efficient allocation absent taxation corresponds to an increasing profile of matches $(b, s)$. This profile is illustrated on Figure 6 using a wiggly solid gray line. If these matches were to remain when the tax is introduced, a match corresponding to point $X$ on the figure would be the highest priced one that is not subject to taxation, the match marked by $Y$ would be the lowest priced one that does not shift to the notch, and matches between $X$ and $Y$ would move to the notch.

Introduction of the tax may affect which matches take place in the equilibrium. The efficient allocation will retain the main features visible on Figure 6, although the actual equilibrium profile and points $X$ and $Y$ need not coincide with the allocation absent tax distortions. As argued above, the equilibrium matches subject to the tax will continue to be assortatively matched - that is, matches above point $Y$ will lie on an increasing profile. Similarly, matches below point $X$ will form an upward-sloping profile. For matches that are priced at the threshold, the price is fixed at $H$ so that any permutation of residences between buyers would deliver exactly the same surplus (a feature that is arguably peculiar to this model), so that the precise identity of matches between $X$ and $Y$ is indeterminate. ${ }^{11}$

The equilibrium allocation in the presence of frictions will not be efficient, although efficiency serves as a natural reference point. Trivially, our theoretical framework implies that under the efficient allocation variance of the price (or, equivalently, buyer's type) conditional on seller's type (and vice versa) is zero, because the efficient allocation corresponds to an upward sloping line. ${ }^{12}$ In the presence of frictions, matches would occur not just on the efficient allocation line as in Figure 6, but rather could be spread over the rest of the region corresponding to surplus from

\footnotetext{
${ }^{11}$ The location of $X$ and $Y$ may change because fewer transactions may take place in the presence of a tax. Figure 6 appears to preclude this possibility by using the efficient matching schedule that does not involve matches that are crowded out by the tax, but it need not be so in general.

${ }^{12}$ While the efficient allocation is not unique in the bunching region $\mathrm{A}$ and $\mathrm{B}$ on Figure 6, the price is constant and equal to the threshold level in that region.
} 
transacting. Intuitively, one might expect that an increase in dispersion of prices for a given type of home corresponds to an allocation that is further from the efficient one. While we do not prove this result, it has to be so at least when the frictions are small. To examine whether transaction taxes affect the efficiency of the housing market allocation, we test whether there is an increased dispersion of prices in the presence of the tax. Because matches are indeterminate in the bunching region, this exercise is of interest for transactions that are not local to the threshold-i.e., those far enough from the threshold in either direction. We discuss this further in Section IIID.

\section{Measuring the Impact on the Price Distribution}

We expect that the tax affects the distribution of home sales by inducing both bunching of sales at the notch and by creating a "gap" in the distribution above the notch, and we estimate both. Our objectives are twofold. First, descriptively, these estimates allow us to quantify the magnitude of distortions to the price distribution. Second, we use these estimates to back out values analogous to the mass in regions $A$ and $B$ of Figure 6. Intuitively, extra transactions bunching at the threshold correspond to regions $A$ and $B$, while transactions that are missing from the distribution above the threshold (relative to the distribution further to the right) reflect region $B$. In principle then, these values may be used to recover the mass in region $A$ that is tightly linked to the bargaining parameter, $\beta$.

However, in what follows, we argue that the tax notch provides a strong incentive for neighboring "productive" matches - those close to the boundary between regions $B$ and $C$, which have positive surplus in the presence of the tax-to break. Consequently, there may be more transactions missing from the distribution above the notch than located at the notch itself. We show that our estimates can be used to test for and bound this local extensive-margin response: if such a response is not present, the excess number of transactions at the notch must exceed the gap in the distribution. We view this test as one of the central contributions of our paper, as it corresponds to testing for unraveling of the market due to the presence of the notch. Equivalently, this is a test of whether the extensive margin response is standard (the gray region in Figure 6) - a condition that is necessary to generalize from estimates based on a notch to behavioral responses to a general tax (as done by Best and Kleven 2013; and Slemrod, Weber, and Shan 2012). Previewing our results, we find that overwhelmingly the answer is that it is not. The rest of this section serves to define quantities that we estimate and to formalize the test for the local unraveling of the market.

Observed and Counterfactual Distributions. - We first consider how the distribution of sales is distorted by the tax notch. The discussion is graphically illustrated on Figure 5, which is a distribution analogue of Figure 6 (with corresponding region labels). We denote by $F(p)$ the "true" (population) price distribution in the presence of the actual (notched) tax from which our observations are drawn. We denote by $F_{T}(\cdot)$ the observed cumulative population price distribution-a draw from $F(p)$. In order to characterize and interpret distortions to the distribution, we presume that 
there is a set of potential matches (from some matching technology) that may result in transactions. We leave the origin of the set of matches unspecified, and simply assume that there is some matching technology that we take as given. Matches are indexed by $i$ and have associated with them three prices $\left(p_{i}, \breve{p}_{i}, \tilde{p}_{i}\right)$ : the actual price $p_{i}$ in the presence of a "notched" tax, the shadow price $\breve{p}_{i}$ that would prevail if the tax did not apply anywhere, and the shadow price $\tilde{p}_{i}$ that would prevail for the same transaction if the tax was proportional everywhere (i.e., involved no threshold). In the context of our model as illustrated on Figure 6, $p_{i}=\breve{p}_{i}$ for transactions taking place in region $D, p_{i}=\tilde{p}_{i}$ in regions $C$ and $E$, and $\breve{p}_{i} \geq H>p_{i}$ in regions $A$ and $B$. Analogously, this respectively corresponds to the transactions far below the notch, transactions above the notch, and the bunching region on Figure 5. We assume that $\breve{p}_{i}>\tilde{p}_{i}$, which excludes the polar case of incidence fully borne by buyers, but allows for simplifying notation. We also allow for either of the prices to be infinite, corresponding to the transaction not taking place in a given regime. We do not rule out in general that the notched tax affects the equilibrium distribution everywhere (even below the threshold): $F(p)$ corresponds to the actual equilibrium outcome; however, $\breve{p}_{i}$ and $\tilde{p}_{i}$ are prices specific to matches that form in the observed equilibrium given a notched tax, so that their marginal distributions do not reflect any changes regarding which matches would form if the tax was removed or replaced by one that is proportional everywhere.

We rely on two counterfactual distributions for our estimates: one that corresponds to the nontaxable regime and another corresponding to the taxable one. $F_{0}(p)=P\left(\breve{p}_{i}<p\right)$ is the counterfactual distribution corresponding to the nontaxable regime. Below the taxable threshold, $H, F_{0}$ is the true distribution net of transactions that are affected by the presence of the $\operatorname{tax}\left(\breve{p}_{i} \geq H>p_{i}\right)$. We define a counterfactual distribution $F_{1}(p)=P\left(\tilde{p}_{i}<p\right)$ corresponding to the region subject to the tax: it is the distribution under a proportional tax with no notch (in particular it is accounting for the "standard" extensive margin response but, of course, without allowing for equilibrium adjustment to the set of matches).

In the presence of the tax, the actual distribution will display an excess mass bunching below the threshold (relative to $F_{0}$ ) and a gap above the threshold (relative to $F_{1}$ ). At some abuse of the notation, we use the region descriptors from Figure 6 (e.g., A) to denote the set of matches and the mass (probability) of transactions in the corresponding region. Transactions that are distorted by the threshold have $\breve{p}_{i} \geq H>p_{i}$ and come from a number of different sources: $\tilde{p}_{i}<H\left(\right.$ region $A$ except for $\left.A^{\prime}\right) ; \tilde{p}_{i}=\infty\left(\right.$ region $\left.A^{\prime}\right) ;$ and $\tilde{p}_{i} \geq H(\operatorname{region} B)$. We note that $A+B=P\left(\breve{p}_{i} \geq H>p_{i}\right)$ and $B=P\left(p_{i}<H \leq \breve{p}_{i} \wedge \tilde{p}_{i} \geq H\right)$ $=P\left(p_{i}<H \leq \tilde{p}_{i}\right)$. As discussed in Section IIIA, these transactions move from above the threshold (in absence of the tax) to bunch just below the notch. This movement of sales from above the threshold (and any additional extensive margin response beyond the standard one already embedded in the adjustment to distribution $F_{1}$ ) leaves a gap in the observed distribution just above the notch. 13

\footnotetext{
${ }^{13}$ Transactions to the left of the threshold (region $D$ ) have $p_{i}=\breve{p}_{i}$, and those with $p_{i}=\tilde{p}_{i}$ correspond to regions $C$ and $E$. The gray region--transactions with surplus low enough that the tax crowds them out-have $\breve{p}_{i}<\infty=p_{i}=\tilde{p}_{i}$.
} 
Crowd Out of Productive Matches.-One concern is that not every productive match corresponds to a transaction: i.e., that there may be transactions for which $\tilde{p}_{i}<p_{i}<\infty=p_{i}$-those with sufficient surplus to survive the tax, but that do not occur in the presence of the notch. To see why, recall that our basic framework assumed that equilibrium matches in the neighborhood of the notch form in a way similar to those away from it, with only the outcome of the bargaining process affected. However, proximity to the threshold provides strong incentive for some buyers and sellers in matches near the notch to continue or delay searching (and perhaps not transact in the end at all). Firstly, consider buyer-seller pairs who would move to the threshold if a sale occurs (region $B$ of Figure 6). Sellers in this regionwho face a substantial reduction in sale price in moving to the notch-may prefer searching for a buyer with slightly higher reservation value who is, thus, willing to buy above the notch. Secondly, buyers in the buyer-seller pairs that would transact in the gap region above the notch (region $C$ ) may have an incentive to return to the market to find a seller with slightly lower reservation value.

Whether this type of local extensive-margin response is present is of interest in its own right, corresponding to both an efficiency loss due to a notched tax in markets with search frictions (productive matches that do not transact) and the importance of search in the housing market. We assume that such exits do not occur for transactions below the threshold $\left(\breve{p}_{i}<H\right.$, region $\left.D\right)$ and for transactions that have sufficiently high prices (region $E, \tilde{p}_{i}>\bar{P}$ for some sufficiently large price $\bar{P}$ ). We denote the mass of such exits that comes from matches that could otherwise sell above the threshold in the presence of proportional taxation (regions $B$ and $C$ ) by $M \equiv P\left(H \leq \tilde{p}_{i} \leq \bar{P}<\infty=p_{i}\right)$.

Local Incidence.-Using an estimate of the excess mass bunching at the threshold $(I)$, we can estimate a measure of the incidence of the tax. We define

$$
I=F(H)-F_{0}(H)=P\left(\breve{p}_{i} \geq H>p_{i}\right)=A+B
$$

as the number of observations that shift below the threshold due to the tax. Given the observed distribution $F_{T}$ and an empirical estimate of the counterfactual distribution $\hat{F}_{0}$, we can construct an empirical estimate of the volume of responsive sales making up $I$ as $\hat{I}=F_{T}(H)-\hat{F}_{0}(H)$. In practice, we construct the counterfactual price distribution of sales $\hat{F}_{0}$ by relying on the actual distribution $F_{T}$ to the left of the notch, but omitting sales near it - the specifics are in Section IIIE. The estimate of bunching, $\hat{I}$, is represented by the red/yellow area in the first panel of Figure 5 .

Given an estimate of the counterfactual distribution $F_{0}$ to the right of the threshold, we can also define a dollar measure $\hat{h}$ as

$$
F_{0}(H+\hat{h})-F_{0}(H)=\hat{I}
$$

to represent the magnitude of the shift to the threshold. In other words, $\hat{h}$ is obtained by finding the dollar value such that the integral under the counterfactual to the right of the notch is equal to the excess mass (represented as the shaded area of the first panel of Figure 5). We refer to $\hat{h}$ as a "local" or "reduced-form" incidence of the 
tax. Our preferred interpretation is that, as with the "kinked" budget-set methodology outlined by Saez (2010), $\hat{h}$ represents the average amount of money that is lost (relative to their corresponding nontaxed sale price, $p_{i}$ ) by sellers participating in the marginal transactions affected by the presence of the threshold. However, the value of $\hat{h}$ does not, on its own, inform us about the underlying bargaining power of the two sides of the market and, hence, does not reflect incidence of the tax away from the threshold.

We construct and estimate $\hat{h}$ throughout, but our interpretation of $\hat{h}$ as local incidence depends on assumptions about the nature of the counterfactual distribution. With the exception of our data for New Jersey prior to implementation of the tax, we do not observe $\breve{p_{i}}$ for values greater than $H$ at all. When we use data below the notch to project $F_{0}$ above the notch, the interpretation of $\hat{h}$ requires additional assumptions. If $F_{\tau}(p)$ below the notch coincides with the distribution absent taxation $F_{0}(p)$ (i.e., $p_{i}=\breve{p}_{i}$ for $\breve{p}_{i}<H$ ), then the projected counterfactual above the notch corresponds to the distribution absent taxation as well, so that $\hat{h}$ can be thought of as a reduced form dollar estimate of local incidence (this interpretation also applies when we build our counterfactual using the non-distorted distribution in New Jersey before the tax was introduced). However, if the untaxed part of the distribution (below the notch) is affected by the tax via general equilibrium effects (and so $\left.F_{\tau}(p) \neq F_{0}(p)\right)$, the projection of the counterfactual above the notch, and the dollar value $\hat{h}$ that relies upon this projection, do not have clear interpretations (although $\hat{h}$ remains a convenient way of standardizing mass of sales bunching below the notch). On the other hand, even if $F_{\tau}(p) \neq F_{0}(p)$, our estimate of the excess mass $\hat{I}$ (and unraveling estimates that depend on it) remains valid.

Gap.-We also construct a measure of the gap to the right of the notch by comparing an estimated counterfactual above the threshold to the observed distribution. We presume that there is a known value of $\bar{P}$ such that $F_{1}$ and $F$ coincide for prices greater than $H+\bar{P}$ (by Theorems A.1 and A.2, this has to be so in our framework; also recall that we assumed away exit of productive matches for high enough prices) and define the gap in the distribution as:

$$
G=\left[F_{1}(\bar{P})-F_{1}(H)\right]-[F(\bar{P})-F(H)],
$$

i.e., the difference between the number of transactions taking place in the presence of taxation with and without the notched implementation of the tax. For the estimation, we replace $F$ by $F_{T}$, and $F_{1}$ by its empirical estimate $\hat{F}_{1}$. The estimate of $\hat{F}_{1}(\bar{P})-\hat{F}_{1}(H)$ reflects the expected number of observations in regions $B$ and $C$, while $F_{T}(\bar{P})-F_{T}(H)$ is the actual number of observations in region $C$. Using our definitions, we can show that

$$
\begin{aligned}
G & =P\left(\bar{P} \geq \tilde{p}_{i} \geq H \wedge\left(p_{i}<H \vee p_{i}=\infty\right)\right) \\
& =P\left(p_{i}<H \leq \tilde{p}_{i}\right)+P\left(H \leq \tilde{p}_{i} \leq \bar{P}<\infty=p_{i}\right)=B+M .
\end{aligned}
$$


Recall that $M$ represents the mass of transactions that would have taken place under a proportional tax at prices exceeding the threshold, but do not take place in the presence of the notch. Thus, the gap reflects two effects: exit from the market of productive matches and shift to the threshold.

To reiterate, the gap reflects transactions that are missing from the distribution to the right of the threshold relative to the counterfactual with taxes. In particular, it does not include the standard extensive margin response-matches with surplus small enough that they are no longer economically viable in the presence of the tax (the gray region $Z$ in Figures 5 and 6).

Testing for Market Unraveling.-The gap, G, and behavioral response, I, are related and can be used to test for the presence of market unraveling and, in the absence of unraveling, to estimate $\beta$. Both $G$ and $I$ partially reflect transactions in region $B$-those that would sell at prices higher than the threshold in the presence of a continuous tax, but sell at the threshold when it is discontinuous. Clearly,

$$
G-I=M-A \text {. }
$$

We report an estimate of $\hat{G}-\hat{I}$ converted to a dollar figure: $\hat{Z}=\hat{h} \cdot\left(\frac{\hat{G}}{\hat{I}}-1\right) \cdot 14$ If the market does not unravel in the neighborhood of the notch $(M=0)$, then $G-I=-A \leq 0$. Intuitively, if all buyer-seller matches continue to transact in the presence of the notched tax, then the mass bunching at the threshold should always be at least as large as the gap. Hence, given estimates of $I$ and $G$, we can then test whether the tax destroys productive matches.

REMARK 1: Rejecting a testable hypothesis $\hat{Z} \leq 0$ implies market unraveling $(M>0)$.

If the hypothesis of $M=0$ cannot be rejected, one could construct a straightforward estimate of $\beta$. With no missing sales, $I-G=A$, so that $\hat{\beta}$ would solve $F_{0}(H+\hat{\beta} \cdot T)-F_{0}(H)=\hat{I}-\hat{G} \cdot{ }^{15}$

Previewing our results, however, we find that $\hat{Z} \leq 0$ is rejected or, put differently, we find that the size of the gap is larger than the number of transactions that bunch. We conclude that there are transactions that do not take place because of the proximity to the threshold so that the market (partially) unravels in its neighborhood. 16

\footnotetext{
${ }^{14}$ Alternative definitions would be to define $F_{1}(H+\hat{Z})-F_{1}(H)=\hat{G}-\hat{I}$ or $F_{0}(H+\hat{Z})-F_{0}(H)=\hat{G}-\hat{I}$. The choice we implement has two advantages. First, it is in terms of the distribution $F_{0}$ so that it is directly comparable to $\hat{h}$. Second, knowing $\hat{h}$ (which we report as well) allows for directly recovering an alternative metric of the gap and behavioral response, $\frac{\hat{G}}{\hat{I}}$.

${ }^{15}$ We treat $T$ as a lump-sum tax here for simplicity of exposition; the effect of adjusting for the marginal tax of 1 percent is negligible for the purpose of this exercise.

${ }^{16}$ Naturally, unraveling occurs here because the tax reduces incentives to transact, but in other contexts the incentives may go the other way. Studying a time-notch affecting marriages in Sweden, Persson (2014) compares bunching at the notch and the gap above the notch and finds that in that context discontinuous incentives may encourage transactions at the (time) notch.
} 
One can bound local exit from the market $(M)$ by considering how much missing mass is required to explain our estimates assuming different values of $\beta$. In particular, consider the two extreme cases of $\beta=0$ (buyer captures all surplus) and $\beta=1$ (seller captures all surplus). In the first case, $A=0$, while in the second case $A$ corresponds to the mass in the interval of prices $(H, H+T)$. Noting that $\hat{Z}$ is expressed in dollar terms, the dollar-valued mass in the second case is, thus, $T$. Hence, the implied missing mass when $\hat{Z}>0$ is between $\hat{Z}$ (when $\beta=0$ ) and $\hat{Z}+T$ (when $\beta=1$ ). In our discussion of the results, we will refer to the lower bound $\hat{Z}$.

Finally, note that this discussion provides three qualifications of general interest when relying on notches and kinks in tax schedules for identification. First, for a clean interpretation of our incidence parameter $\hat{h}$ (and, analogously, for estimating elasticities or other measures of behavioral response based on bunching), the counterfactual distribution $F_{0}$ needs to correspond to the situation absent the tax-this is a strong assumption that is violated if there are spillover effects from the notch/ kink to the nontaxable region. However, our estimates of the number of observations bunching $\hat{I}$ and missing mass $\hat{Z}$ do not require such an assumption. Second, the presence of a notch may provide incentives to exit, corresponding to local unraveling of the market. In this case, gap estimates partially reflect such an exit and can be used to test for its presence when combined with the magnitude of the shift to the notch. Third, as a consequence, when there is such market unraveling, extensive-margin responses estimated by studying local effects of notches/kinks do not generalize to extensive response elsewhere.

\section{Implications for Efficiency of the Equilibrium Allocation}

In order to shed a light on how taxation interacts with search frictions away from the threshold in this market, we proceed as follows. Recall that the equilibrium price for a given match $(b, s)$ is equal to $\beta b+(1-\beta) s-\beta T$. Conditional on the seller's type, $\operatorname{var}[p \mid s]=\beta^{2} \operatorname{var}[b \mid s]$. If we could directly observe $s$, the comparison of the variance of prices conditional on $s$ with and without the tax would constitute a test of the hypothesis that taxation affects price dispersion. Evidence of this kind would suggest that the tax increases deviation from efficiency.

In practice, we are unable to observe the seller's type and instead rely on a set of indicators, $X$, that proxy for it. In that case,

$$
\operatorname{var}[p \mid X]=\beta^{2} \operatorname{var}[b \mid X]+(1-\beta)^{2} \operatorname{var}[s \mid X]+2 \beta(1-\beta) \operatorname{cov}[b, s \mid X] .
$$

When $X$ contains $s$, the second and third term are zero. In order to understand how $\beta^{2} \operatorname{var}[b \mid s]$ varies with and without taxation, we consider expanding the set of indicators $X$-as they become more informative about $s$, the influence of the last two terms declines and the first term should tend toward $\operatorname{var}[b \mid s]$. We test whether there is a difference between $\operatorname{var}[p \mid X]$ with and without taxes for a large set of indicators $X$ correlated with seller's type.

One of the primary indicators of seller's type that we consider is the seller's asking price. It is natural to think that this price is correlated with the seller's type, but 
it may also be endogenous to taxation. In that case, the alternative interpretation of the effect of taxation on $\operatorname{var}[p \mid X]$ is as a test of whether taxation changes informativeness of this important signal available to buyers.

\section{E. Econometric Implementation}

We estimate the price distribution of sales by maximum likelihood as follows. We specify a parametric distribution of prices absent the tax:

$$
\ln f_{0}(p)=g(p)+\alpha D(p)
$$

and the distribution in the presence of the tax:

$$
\ln f(p)=\ln f_{0}(p)+\gamma \cdot I(p>H),
$$

where the left-hand side is the log of the probability distribution function at price $p, g()$ is a parametric function (a polynomial-third degree in our baseline specification) and $D$ is a set of controls for round numbers. We allow for discontinuity of the density at the threshold $(\gamma)$ to account for the shift in sale price and global extensive-margin response (gray region $Z$ of Figures 5 and 6) among transactions subject to the tax. We estimate this model using data that excludes some region around the threshold $(H-\underline{P}, H+\bar{P})$ to ensure that our estimates are not biased by the distortions to the distribution near the notch. ${ }^{17}$ Given the observed distribution of prices outside of the omitted region, we estimate the distribution given by equation (3) by maximum likelihood. 18 This procedure yields $\hat{f}_{0}(p)$, our estimate of the counterfactual distribution function of prices absent the tax and $\hat{f}_{1}=e^{\hat{\gamma}} \hat{f}_{0}$, the counterfactual in the presence of the tax. ${ }^{19}$ Using these counterfactual distributions, we estimate bunching and gap, local incidence, and bounds on attrition near the threshold as outlined above. Specifically, we estimate the excess mass as the difference between the observed mass in the region $(H-\underline{P}, H)$ and the predicted mass $\left(\int_{H-\bar{P}}^{H} \hat{f}_{0}(p) d p\right)$, and estimate the gap as the difference between the predicted mass in the region $(H, H+P)$ allowing for a discontinuity at $H\left(\int_{H}^{H+\bar{P}} \hat{f}_{1}(p) d p\right)$ and the observed mass in $(H, H+\bar{P})$.

While it is common in existing literature exploiting kinks and notches for identification to include round-number dummies to control for bunching at these points, our implementation of the round-number effects, $D(p)$, is more involved. Our baseline approach is to rely on the maximum likelihood estimation and, hence, specify the density at any point. In order to parsimoniously capture various forms of bunching (in particular, there is bunching in listings data just under round numbers-e.g., at

\footnotetext{
${ }^{17}$ Our theoretical framework establishes that there is a value of $\bar{P}$ above which the notch (although not the tax) is irrelevant for the distribution.

${ }^{18}$ Formula 3 is already the log-likelihood and implementation only requires imposing conditions guaranteeing that $f(p)$ is a probability distribution function, i.e., that it integrates to one over the considered interval.

${ }^{19}$ We show as a robustness check an estimate of $\hat{h}$ resulting from estimating $f_{0}$ using only the data to the left of the threshold. Moreover, we combine this with an estimate of $f_{1}$ using only data on the right of the omitted region to attain an estimate of $\hat{Z}$.
} 
$\$ 899,000)$, we introduce "bunching" regions for each round number $R$ that extend from $R-b$ to $R$. Within the bunching regions, the distribution is specified as $g(p)+D_{R}+D_{R} \cdot p$, where $D_{R}$ are the relevant round-number dummies, while it is $g(p)$ otherwise. Interacting the round-number dummies with price allows the extent of rounding to vary with price (perhaps $\$ 1.2$ million is not equally as salient as $\$ 600,000)$. In practice, we allow for rounding at multiples of $\$ 25,000$, but allow for separate effects for multiples of $\$ 25,000$ and $\$ 50,000$. We set $b=\$ 1,000$, which makes the bunching region extend from, for example, $\$ 899,000$ to $\$ 900,000$ allowing both for bunching at the $\$ 900 \mathrm{~K}$ level and just below it (e.g., $\$ 899,999)$. Since our objective is to estimate the counterfactual in the omitted region (in particular, at $\$ 1$ million), this approach amounts to assuming that bunching at other round prices is a valid counterfactual for the magnitude of bunching at the tax notch - this is not a directly testable assumption but, as discussed before, data in New Jersey before the introduction of the mansion tax (Figure 3) provides support for this assumption. Except for a gain in information by allowing for continuous prices, this approach is very close to binning the data in $\$ 1,000$ bins (and we show the more restrictive "binned" specifications as one of our robustness checks). Beyond that, using maximum likelihood instead of fitting a polynomial to binned data replaces the arbitrary zero-mean restriction for the error terms by a natural restriction that the estimated specification represents a distribution function-arguably, a much more natural assumption than OLS.

All reported standard errors are obtained by bootstrapping the whole procedure 999 times. Note that the estimates of incidence and gap may fall into one of the round-number bunching regions. When this is the case, the estimates are not very sensitive-small changes in parameters correspond to staying in the bunching region. In such cases reported standard errors for estimates of gap and incidence are small, even though standard errors for parameters of the parametric density are not.

\section{Distortion to the Price Distribution}

We begin by demonstrating graphically that the tax has a causal effect on the distribution of prices and timing of transactions. Response to the tax notch is evident in Figure 1, which shows the empirical distribution of taxable sales in New York with sales grouped into $\$ 5,000$ bins. There is clear bunching in the sale price just below $\$ 1$ million and a drop in the volume of sales just above $\$ 1$ million. These features, especially the gap above the notch, are obvious when looking at the distribution in logarithmic scale (and $\$ 25,000$ bins), as in Figure 2. Figure A1 in the online Appendix shows analogous patterns at the smaller (0.425 percent) RPTT notch at $\$ 500,000$, which also demonstrates some evidence of a response. ${ }^{20}$

\footnotetext{
${ }^{20}$ There is also significant bunching at other round price levels (at every $\$ 50,000$ and, to a lesser extent, remaining \$25,000 multiples), which may confound our bunching analysis. Unlike the bunching at \$1 million, this round-number bunching occurs in the bin above rather than the one below the round number. A priori it is possible that, although this observed bunching below $\$ 1$ million is consistent with theoretical predictions, it may simply reflect adjustments to the tax by very small amounts. However, aggregating the data to larger bins in Figure A2 mostly eliminates such round-number bunching, while continuing to indicate that the response covers more than just the immediate neighborhood of the threshold.
} 
We can also verify explicitly that the tax induces bunching by comparing sales in New Jersey before and after the introduction of the tax. Figure 3 presents plots of the (log-scaled) histogram of sales in New Jersey before and after the tax is introduced in $\$ 25,000$ bins, with the pretax distribution adjusted to account for sales growth and inflation, as discussed in the figure note (and corresponding to our later empirical implementation that compares New Jersey before and after the tax). ${ }^{21} \mathrm{We}$ see pronounced bunching after the tax is introduced in 2004 and minimal bunching prior to 2004. Data prior to 2004 also shows that $\$ 1$ million is no more salient than other multiples of $\$ 50,000$ before the tax arrives. Moreover, this figure displays clear visual evidence of the gap above the notch in the post-tax distribution, a feature that is not shared with the pre-tax distribution.

As Figure 4 illustrates, the number of sales in New Jersey just below the threshold clearly increases precisely at the time of the introduction of the tax and the number of sales above the threshold falls. Focusing on the region within $\$ 10,000$ of the threshold it is evident that the increase in the mass below the threshold is larger than the shift from just above $\$ 1$ million. This difference provides the first clear indication that the local effect of the tax may extend beyond 100 percent of its value $(\$ 10,000)$. Figure A3 in the online Appendix demonstrates that retiming is strong for sales well above the threshold, but that it is unlikely to have lasted for an extended period of time- - the excess sales just before the introduction of the tax do not correspond to more than a couple months worth of sales. On the other hand, the pattern of sales in the combined $\$ 900,000-\$ 1,100,000$ range suggests that, despite pricing effects post-introduction of the tax, overall retiming of transactions in the neighborhood of the threshold is not particularly strong. ${ }^{22}$

Our baseline estimates, presented in Table 5, demonstrate that the observed bunching translates to a local incidence on sellers that exceeds the magnitude of the tax. The first row reports estimates for New York City and corresponds to the specification shown on Figure 2. For our baseline, we use a third order polynomial, while omitting data in the $\$ 990,000-\$ 1,155,422$ region (the upper bound is the theoretical limit discussed in Section IIIA), and allowing for an additional constant shift above the tax threshold. Our estimate of the local incidence parameter in the baseline specification is $\$ 21,542.098$ : bunching at the threshold is equivalent to all transactions over the following $\$ 21,000$ shifting to the threshold. These estimates are consistent with impressions from the graphical evidence presented above. Taken literally as an incidence estimate this corresponds to over 200 percent incidence of the tax on

\footnotetext{
${ }^{21}$ We choose this larger bin size to smooth out the bunching at other multiples of $\$ 50,000$. The conclusions are the same using $\$ 5,000$ bins - in the presence of the tax there is excess bunching just below $\$ 1,000,000$ and a gap just above that is not present when there is no tax. However, the bunching at multiples of $\$ 50,000$ makes the figure difficult to read when both distributions (pre and post tax) are overlaid.

${ }^{22}$ Appendix Figure A4, which shows the monthly distribution of sales in New Jersey between $\$ 900,000$ to $\$ 1,100,000$, further demonstrates that responses extend well beyond the $\$ 10,000$ value of the tax. There is no evidence of the distribution being distorted below $\$ 975,000$, and clear evidence of a shift of the mass of sales to just under $\$ 1$ million from as far above as the $\$ 1,025,000$ to $\$ 1,050,000$ range. Additionally, Figures 4 and A4 show patterns that may be consistent with anticipation effects--there is a spike in sales with prices over $\$ 1$ million just before the introduction of the tax. This is not surprising: the tax had been announced prior to coming into effect, and the lengthy process of closing a real estate transaction may allow for the possibility to speed up the timing of final sale. This effect is not long lasting and of no relevance for New York where the tax was introduced long before our data starts.
} 
Table 5-Response to Mansion Tax, by Region and Years since Construction

\begin{tabular}{|c|c|c|c|c|c|c|}
\hline \multicolumn{2}{|l|}{ Sample } & Incidence & SE & $\hat{Z}$ & SE & $n$ \\
\hline \multicolumn{2}{|l|}{$\begin{array}{l}\text { sample } \\
\text { NYC }\end{array}$} & $21,542.098$ & $1,150.878$ & $43,861.766$ & $4,142.953$ & 102,493 \\
\hline \multicolumn{2}{|l|}{ NYS (excl. NYC) } & $23,227.515$ & $1,084.482$ & $41,610.588$ & $4,334.170$ & 108,462 \\
\hline \multicolumn{2}{|l|}{ NJ post-tax } & $21,477.388$ & $1,474.300$ & $37,409.873$ & $4,310.896$ & 111,936 \\
\hline \multicolumn{2}{|l|}{ NJ pre-tax } & -784.065 & 38.892 & $2,958.261$ & 285.872 & 57,836 \\
\hline \multicolumn{2}{|l|}{ NJ pre/post comparison ${ }^{\mathrm{a}}$} & $25,000.000$ & $8,515.132$ & $14,223.330$ & $11,628.94$ & 2,020 \\
\hline $\begin{array}{l}\text { NYC (years since } \\
\text { construction) }\end{array}$ & $\begin{array}{c}<0 \\
0 \\
1 \\
2 \\
3 \\
4-6 \\
7+\end{array}$ & $\begin{array}{l}37,329.701 \\
13,759.258 \\
11,309.339 \\
14,118.294 \\
24,467.069 \\
25,586.634 \\
22,780.508\end{array}$ & $\begin{array}{r}16,009.929 \\
7,671.441 \\
3,457.124 \\
3,145.743 \\
5,927.603 \\
6,045.138 \\
1,275.592\end{array}$ & $\begin{array}{r}-13,709.572 \\
-2,451.076 \\
45,053.550 \\
47,311.896 \\
36,654.826 \\
82,880.894 \\
48,877.574\end{array}$ & $\begin{array}{r}42,837.004 \\
27,109.852 \\
15,619.853 \\
15,259.170 \\
26,001.895 \\
29,444.354 \\
5,193.370\end{array}$ & $\begin{array}{r}559 \\
1,048 \\
3,422 \\
4,388 \\
2,253 \\
2,433 \\
72,128\end{array}$ \\
\hline NYS (excluding NYC) & $\begin{array}{l}\text { Old } \\
\text { New }\end{array}$ & $\begin{array}{l}22,677.619 \\
34,254.287\end{array}$ & $\begin{array}{l}1,283.443 \\
8,350.604\end{array}$ & $\begin{array}{l}40,945.774 \\
62,173.984\end{array}$ & $\begin{array}{r}4,264.702 \\
25,965.831\end{array}$ & $\begin{array}{r}104,576 \\
3,886\end{array}$ \\
\hline $\begin{array}{l}\text { NJ post-tax } \\
\quad(\text { years since construction) }\end{array}$ & $\begin{array}{c}0 \\
1 \\
2 \\
3 \\
4-6 \\
7+\end{array}$ & $\begin{array}{l}24,949.365 \\
24,684.039 \\
23,730.361 \\
24,950.530 \\
19,718.802 \\
19,967.636\end{array}$ & $\begin{array}{r}10,542.512 \\
7,485.882 \\
7,183.484 \\
8,043.393 \\
4,392.694 \\
1,633.977\end{array}$ & $\begin{array}{l}19,598.806 \\
55,501.171 \\
54,344.928 \\
25,353.913 \\
41,103.750 \\
40,047.784\end{array}$ & $\begin{array}{r}33,121.546 \\
26,732.423 \\
25,413.421 \\
25,917.361 \\
17,066.774 \\
4,989.520\end{array}$ & $\begin{array}{r}988 \\
1,896 \\
1,773 \\
1,882 \\
6,148 \\
85,551\end{array}$ \\
\hline $\begin{array}{l}\text { NJ pre-tax } \\
\quad(\text { years since construction) }\end{array}$ & $\begin{array}{c}0 \\
1 \\
2 \\
3 \\
4-6 \\
7+\end{array}$ & $\begin{array}{r}-351.083 \\
-142.337 \\
-798.644 \\
-2,121.267 \\
-661.898 \\
-778.278\end{array}$ & $\begin{array}{r}4,149.632 \\
6,362.861 \\
1,743.317 \\
2,519.545 \\
537.723 \\
46.481\end{array}$ & $\begin{array}{l}1,619.879 \\
4,103.325 \\
3,214.845 \\
8,725.490 \\
9,250.812 \\
3,226.236\end{array}$ & $\begin{array}{r}26,316.982 \\
71,219.647 \\
13,783.929 \\
10,998.073 \\
18,873.573 \\
380.842\end{array}$ & $\begin{array}{r}723 \\
852 \\
1,082 \\
1,249 \\
3,335 \\
36,530\end{array}$ \\
\hline
\end{tabular}

Notes: Estimates from baseline procedure (third-order polynomial, omit $\$ 990 \mathrm{k}-\$ 1,155,422$ ). New Jersey sample restricted to sales recorded between 1996 and 2003 for pre-tax estimates and after August 2004 for estimates in presence of the tax. Years since construction defined as the difference between the year the property was built and the year of sale. New sales in New York State are defined as any being flagged as new construction.

${ }^{a}$ Estimates for New Jersey pre/post comparison using New Jersey taxable sales omitting 90 days around the implementation of the policy: from Oct. 30, 2004 to Oct. 29, 2005 (postperiod) and May 3, 2003 to May 2, 2004 (preperiod). Incidence estimate is the price at which the number of sales in the preperiod to the right of the threshold equal the difference between the number of sales in the bunching region $(\$ 990,000-\$ 999,999)$ in the postperiod and adjusted preperiods_-preperiod distribution is adjusted as described in text. $\hat{Z}$ calculated as in the text, where the excess number of sales bunching at the gap is the difference between the post- and adjusted preperiod distributions in the bunching region, while the gap is calculated as the difference between the distributions above the notch $(\$ 1 \mathrm{M}-\$ 1,155,422)$. Number of observations listed for the pre/post comparison is the total count of taxable sales between $\$ 990,000$ and $\$ 1,155,422$ for these dates.

Source: New York City data is from the Department of Finance Rolling Sales file for 2003-2011 (taxable sales defined as single-unit, noncommercial sales of one-, two-, or three-family homes, co-ops, and condos). Data for New York State from the Office of Real Property Services deeds records for 2002-2006 and 2008-2010 (taxable defined as all single-parcel residential sales of one-, two-, or three-family homes). Data for New Jersey from the State Treasury SR1A file for 1996-2011 (taxable defined as any residential sale).

sellers for the marginal transaction. The fourth column presents the corresponding estimates of $\hat{Z}$ : the positive value indicates that there has to be substantial unraveling due to the presence of the threshold or, in other words, there is no $\beta$ that can rationalize behavior if no such extensive-margin response is present.

In online Appendix $\mathrm{C}$, we discuss robustness of these results to reasonable modifications of our specification, including choice of polynomials, changes in the 
omitted region and estimating incidence by OLS relying on binned data. We find that our baseline local incidence results are very robust. We also consider "placebo" treatments at other round numbers that, as expected, show no effect.

Our estimate of about 200 percent reduced-form incidence local to the threshold is consistent across geographies and datasets. In the top panel of Table 5, we report results for New York State (excluding New York City) and New Jersey. Estimates for these regions are remarkably similar-within $\$ 2,000$ - to those for New York City. In contrast, estimates for New Jersey before the introduction of the tax show no evidence of bunching.

As an alternative to our maximum likelihood approach, we estimate incidence in New Jersey using the pre-tax period as a counterfactual for the post-tax period and find similar results. We implement this pre/post comparison as follows. We omit transactions within 90 days of the policy change (to avoid the retiming response) and focus on the following year (October 30, 2004 to October 29, 2005). We rescale the period before the tax (May 3, 2003 to May 2, 2004) to account for sales growth over time. Specifically, we construct a counterfactual growth factor by taking the ratio of the count of sales within $\$ 2,500$ of each price from May 3, 2002 to May 2, 2003 to the count of sales from November 5, 2000 through November 4, 2001 (omitting sales between November 2001 and May 2002 to mimic the 180 day gap around the introduction of the tax in August, 2004). Figure 3 shows the corresponding distributions. We find excess sales at the mansion tax threshold as the difference between total postperiod sales and adjusted preperiod sales in the region $\$ 990,000-\$ 999,999$, and estimate the incidence as the price, $p^{*}$, at which the number of sales in the preperiod between the threshold and $p^{*}$ is equal to the excess. We estimate the missing mass in the gap in the same way by taking the difference between total sales in the range $\$ 1,000,000-\$ 1,155,422$ in the preperiods and postperiods. We find standard errors for these estimates by bootstrapping this procedure (including the growth factor for the preperiod) 999 times. Our incidence estimate using the pre/post comparison is slightly larger than the baseline estimate $(\$ 25,000$ versus $\$ 21,542){ }^{23}$ The similarity of our estimate of $\hat{h}$ using cross-sectional data (our baseline specification) and the pre/post comparison in New Jersey is reassuring, given that these sources of identification rely on different assumptions about the counterfactual. In the cross-sectional case, the counterfactual distribution is potentially distorted due to general equilibrium effects. In the pre/post comparison, the counterfactual is the distribution absent taxation. Similarity of the estimates of $\hat{h}$ suggests that general equilibrium spillover to the distribution outside of the omitted region is not very important.

We find some heterogeneity by property vintage (years since construction) in estimates shown in Table 5, suggesting that some of the local response to the tax may

\footnotetext{
${ }^{23}$ We find little change in local incidence over time. Figure A5 in the online Appendix displays monthly incidence estimates for New Jersey. Prior to the introduction of the mansion tax in August 2004 estimates show no response to the threshold. Once the tax is introduced, prices quickly respond-incidence estimates reach the $\$ 20,000$ level within four months. We find no evidence that the response to the tax is changing with the housing boom and bust. We also see no obvious relationship between incidence and the real estate market in New York. Table A3 presents incidence estimates for all three geographies over time. While the estimates vary somewhat from year to year and region to region, we see no clear pattern over time and they all hover around our baseline estimates of $\$ 20,000$.
} 
be due to supply-side quality adjustments. We expect that negotiating a purchase of property before construction is finished allows for significant response in terms of the level of finish, appliances, and other amenities, allowing for price reductions driven by adjustments in property characteristics. Similarly, older properties may require renovation and hence allow for quality to more readily respond to the tax. In contrast, original sales of apartments or houses after they have been constructed and finished may have less flexibility. Our data for New York City and New Jersey contain information about year of construction of the property. In particular, in New York City, which is dominated by large apartment buildings, there is a nontrivial number of sales that occur before construction is finished. For New York (but not New Jersey), we find that bunching is very large for sales before construction is complete and for sales that occur three or more years after construction. In contrast, sales that occur soon after construction-presumably original sales of already fully constructed and equipped properties-show smaller, but still significant (exceeding $\$ 10,000$ incidence estimate), bunching. Recall though that the introduction of the tax in New Jersey induced bunching immediately (Figures 4 and A4), so that investment-related adjustments are unlikely to explain the bulk of the response. We interpret these results as evidence that supply-side response along the quality/finish dimension is important: quality adjustments may perhaps explain around half of the price shift, still leaving local incidence of over 100 percent. While we do not pursue full welfare analysis, note that such a tax-motivated response corresponds to welfare loss by the same logic that implies that taxable income response reflects the efficiency cost of income tax (Saez, Slemrod, and Giertz 2012).

Our estimates for the NYC RPTT and NJ RTF, reported in the first and second panels of Table 6, are smaller, but still consistent, with the mansion tax results. We find no evidence of response to the small (\$600) New Jersey RTF threshold. For the $\$ 2,125$ RPTT notch that applies only in New York City, we find a response for new sales, but not for old sales (and we find no effect in the rest of New York State where the tax does not apply). The variability of these results coincides with shifts in statutory incidence. Like the mansion tax, the RPTT on new sales is the responsibility of the buyer and we find evidence of a response that is consistent with the mansion tax estimates, albeit somewhat smaller: $\$ 1,758.225$ represents an 82.7 percent local incidence on sellers of the $\$ 2,125$ increase in tax liability. The RPTT on old sales and the New Jersey RTF schedule are the responsibility of the seller, and in none of these cases do we find any evidence of response. Both of these results are consistent with our reduced-form incidence estimates based on the mansion tax: a 100 percent burden of the tax on sellers should correspond to no price change for the sellers when they are the party with statutory incidence. Alternatively, switching incidence can correspond to changes in the salience of the tax-perhaps a tax imposed on sellers is less salient than the one imposed on the buyers. ${ }^{24}$

\footnotetext{
${ }^{24}$ For both the RTF and the RPTT there is a small dominated region where sellers would be better off accepting a lower sale price below the threshold, which is offset by a lower tax bill. Thus, there should be a small amount of bunching and a small gap at the RTF and RPTT thresholds when sellers remit. That we find no evidence of this is potential support of these taxes' limited salience. The dollar value of these discontinuities is small, however, so we refrain from drawing sharp conclusions on this point.
} 
Table 6-Heterogeneity in Response by Notch and Subsample

\begin{tabular}{llrrrrr}
\hline \hline Geography & \multicolumn{1}{c}{ Sample } & Incidence & SE & $\hat{Z}$ & \multicolumn{1}{c}{ SE } & $n$ \\
\hline RPTT & & & & & & \\
NYC & New & $1,758.225$ & 751.923 & $3,071.659$ & $1,975.290$ & 21,683 \\
& Old & -390.461 & 28.339 & 488.460 & 69.802 & 259,840 \\
NYS & New & -679.032 & 510.129 & 7.829 & 332.599 & 19,147 \\
& Old & -889.542 & 18.945 & 1105.190 & 56.531 & 687,807 \\
& & & & & & \\
RTF & & & & & & \\
NJ & Post Aug. 2004 & -699.552 & 15.333 & -268.101 & 44.131 & 546,882 \\
& Pre Aug. 2004 & -591.400 & 20.099 & -300.348 & 68.344 & 836,832 \\
Mansion Tax & & & & & & \\
NYC & All co-ops & $16,292.354$ & $2,184.555$ & $58,245.269$ & $8,590.430$ & 26,950 \\
& All non-co-ops & $23,292.602$ & $1,027.253$ & $38,817.535$ & $4,612.629$ & 75,543 \\
& Old non-co-ops & $24,196.113$ & 535.699 & $37,340.124$ & $5,067.660$ & 63,971 \\
NYC deeds & Cash only & $16,018.361$ & $2,356.852$ & $74,976.653$ & $8,814.378$ & 28,339 \\
& Mortgage & $20,676.666$ & $2,223.237$ & $119,838.215$ & $11,273.628$ & 49,421 \\
NYS & Arms-length & $23,168.557$ & $1,163.640$ & $43,274.495$ & $4,606.535$ & 97,936 \\
& Non-arms-length & $23,786.484$ & $3,149.902$ & $24,496.898$ & $12,693.600$ & 10,526 \\
\hline
\end{tabular}

Notes: RPTT and RTF estimates based on 5th-order polynomial, omitting sales between $\$ 490,000$ and $\$ 550,000$ (for NYC and NYS) and between $\$ 340,000$ and $\$ 400,000$ (for NJ), mansion tax estimates as in the baseline specification. New York City data is from the Department of Finance Rolling Sales file for 2003-2011. Sales in New York City are defined as single-unit noncommercial sales of one-, two-, or three-family homes, co-ops, and condos. New sales are defined as any sale occurring within three years of unit's construction (in NYC) or any sale flagged as new construction (in NYS, excluding NYC). Co-ops are identified in the rolling sales data as sales with associated building codes equal to "Co-ops-Walkup Apartments" or "Co-ops-Elevator Apartments." New York City Deeds Records data from deeds records collected by private data provider (taxable defined as any residential sale). Non-arms-length sales in New York State defined by the Office of Real Property Services as a sale of real property between relatives or former relatives, related companies or partners in business, where one of the buyers is also a seller, or "other unusual factors affecting sale price" (ex. divorce or bankruptcy).

Source: Data for New York State from the Office of Real Property Services deeds records for 2002-2006 and 20082010 (excluding NYC) restricted to all single-parcel residential sales of one-, two-, or three-family homes. Data for New Jersey from the State Treasury SR1A file for 1996-2011 (taxable defined as any residential sale).

One concern is that the response to the tax may be driven by tax evasion, which we investigate by examining proxies for the availability of evasion opportunities. In the third panel of Table 6, we split the New York City sample by co-op versus condo status. Co-op transactions have to be approved by co-op boards that have the power to veto sales. In particular, there is anecdotal evidence that co-op boards disapprove transactions that occur below the expected (or, perhaps, desired) market price. One might expect that if underreporting of the price is the important margin of response to the tax, the extent of bunching in co-op apartments should be smaller than otherwise. This is indeed what we find, although the margin is small: $\$ 16,292.354$ for co-ops versus $\$ 23,292.602$ for non-co-ops.

We also investigate a more direct proxy for evasion - the nature of the transaction - presented at the bottom of Table 6. All cash transactions involve fewer parties (in particular, no financing) and more liquidity, which may increase the likelihood of side payments. We find the opposite: incidence of $\$ 16,018$ for cash transactions versus $\$ 20,676.666$ when the sale has an associated mortgage. In the context of real estate transactions, tax evasion is certainly possible, but one might expect that it is not completely straightforward: both parties have to agree and money has to change hands at some point during the long closing process. Evasion in this context 


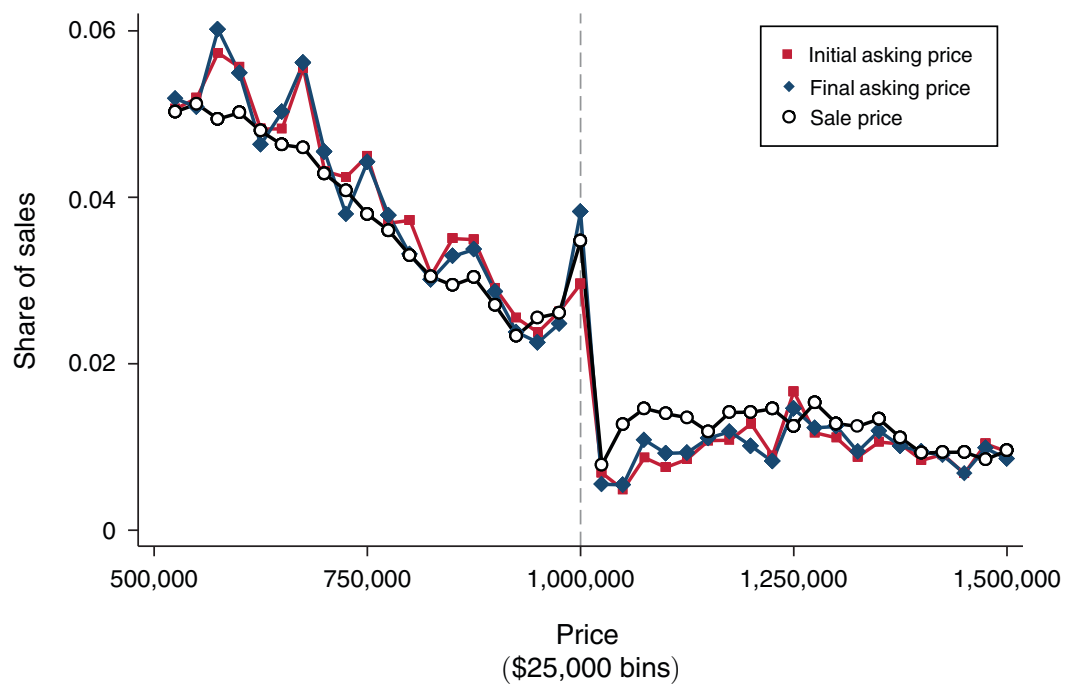

Figure 7. Distribution of Real-Estate Listing Prices in New York City (sold properties only)

Notes: Sample restricted to "sold" listings: last listing status is "closed" and property can be matched to New York City sales data. Smoothed plot of the distribution that accounts for round-number bunching. The log of the per$\$ 25,000$-bin counts are regressed on a cubic in price and dummy variables for multiples of $\$ 50,000$ and $\$ 100,000$ interacted with the price. Predicted bunching for round-number bins are then subtracted from the corresponding counts.

Source: Data from REBNY listings matched to New York City Department of Finance sales records.

likely requires an aspect of trust between the two parties. Our New York State data contains a dummy for whether a transaction is "arms-length" (i.e., between related parties). We find no evidence that arms-length transactions involve more bunching ( $\$ 23,169$ for arms-length sales, $\$ 23,786$ for nonarms-length).

Finally, examining listings data for Manhattan, we find comparable bunching in seller listing prices, suggesting that evasion is not a driving force of the observed sale-price response. Figure 7 shows the smoothed distribution of listing prices around the mansion tax threshold for properties sold and matched to the tax data. ${ }^{25}$ There are three prices shown for sold listings: the initial asking price, the final price in the listing data, and the sale price. Among properties that sell, bunching appears most prominent for the final asking price, followed by the sale price, and the initial asking price. These visual perceptions are confirmed by our estimates in Table 7 that find substantial bunching for both initial and final listing prices that actually exceed the response at the sale stage. ${ }^{26}$ The response of the listing prices indicates that

\footnotetext{
${ }^{25}$ Since bunching is more prominant in listings data, we adjust the distributions on the graphs to remove the common round number bunching. Specifically, we regress the log of the per-\$25,000-bin count on a cubic in price and dummy variables for multiples of $\$ 50 \mathrm{k}$ and $\$ 100 \mathrm{k}$ interacted with the price. We then subtract the predicted bunching effect from the actual counts. The remaining peaks in the data are the result of noise and do not necessarily correspond with salient round numbers. Figure A6 and Figure A7 in the online Appendix show the unadjusted distribution and the distribution of listing prices for all listed properties in Manhattan, respectively.

${ }^{26}$ We do not find conclusive evidence of a similar response of listings prices to the New York City RPTT. This is consistent with the results that we discussed before: we find a response to the RPTT only for new sales where the tax applies to buyers. However, the number of new sales in the listing data is very small and we run into power issues.
} 
TABLE 7-MANSION TAX: LisTingS

\begin{tabular}{lcccccc}
\hline \hline Sample & Price & Incidence & SE & $\hat{Z}$ & SE & $n$ \\
\hline All & First & $24,443.666$ & 166.150 & $101,702.509$ & $10,589.033$ & 36,232 \\
& Final & $34,992.894$ & $3,380.599$ & $76,606.311$ & $9,122.157$ & 35,714 \\
Sold & & & & & & \\
& First & $24,363.369$ & 353.901 & $95,113.750$ & $12,794.903$ & 25,112 \\
& Final & $38,445.445$ & $4,289.510$ & $68,828.242$ & $10,640.681$ & 24,755 \\
& Sale & $19,148.096$ & $2,089.630$ & $53,521.404$ & $8,077.065$ & 24,474 \\
Unsold & & & & & & \\
& First & $24,700.339$ & $2,638.516$ & $113,962.040$ & $21,381.710$ & 7,612 \\
& Final & $32,926.816$ & $6,670.229$ & $94,839.590$ & $19,962.747$ & 7,539 \\
\hline
\end{tabular}

Notes: Unsold sample defined as all listings with final status not equal to "closed." Sold sample defined as all listings that match to a New York City Department of Finance sale record with final status equal to "closed." First price is the initial price posted on the listing. Final price is the last price posted while the listing is active (prior to status being changed to "in contract" or "off market"). Sale price is the recorded price from the New York City Department of Finance.

Source: Data from the Real Estate Board of New York's listing service; represents all REBNY listings between 2003 and 2010 that are closed or off market.

sellers internalize the presence of the tax (which is the responsibility of the buyer) even before meeting the buyer. Since these listings responses occur before the seller identifies a buyer who would be willing to engage in tax evasion, we find it unlikely that the ultimate sale price response is driven by such cheating.

The evidence so far shows clearly that notched transaction taxes distort the distribution of sale prices. We find some evidence of supply-side response in quality adjustments, as well as differences in estimates based on the side of the market responsible for the tax. Our tests of tax evasion are weak, but do not suggest that this is the main force. These results reflect local reduced-form incidence estimates-the adjustment of prices in response to the threshold. By themselves, they do not reveal the strength of bargaining power and are not informative about the incidence of the tax away from the threshold. As discussed in our theoretical section, understanding the bargaining power and, relatedly, the possibility of unraveling in the market requires investigating the size of the gap in the distribution as well (reflected by $\hat{Z}$ ).

\section{Unraveling: Market Distortions Local to the Threshold}

Our estimates of $\hat{Z}$ imply that there is significant unraveling of the market local to the tax threshold. In general, we find the number of sales bunching at the threshold to be smaller than the number of sales missing from the gap, translating into a positive value of $\hat{Z}$, as reported in Table 5. As discussed in Section IIIC, a positive sign on $\hat{Z}$ cannot be reconciled with positive values of $\beta$ (seller's bargaining power), and instead indicates unraveling of the market in the proximity of the threshold. Hence, our results show that the threshold design of the tax discourages transactions that would have taken place if the tax rate was the same but discontinuity was not present - even after controlling for the usual extensive margin response (sales with positive surplus in absence of the tax, but negative surplus when taxed) we find that there are sales that do not occur. Moreover, the presence of unraveling suggests that the matching process is an important part of real estate sales and that this process may be disrupted by the tax. 
To be specific, our baseline estimate of $\hat{Z}=\$ 43,861.766$ implies that the tax eliminates transactions that correspond to a range of original prices with a width between $\$ 43,861.766$ and $\$ 43,861.766+$ tax $\approx \$ 54,000$ above the threshold. For New York City, this corresponds to about 2,800 sales over the 2003-2011 period. Altogether, we find that the tax induces a $\$ 20,000$ price-range worth of transactions from above the threshold to bunch at the threshold, and discourages another $\$ 50,000$ or so of sales from occurring at prices just above the threshold. The finding that $\hat{Z}$ is substantial and positive is robust. First, as can be seen in Table $5, \hat{Z}$ ranges from $37,409.87$ to $43,861.766$ across the three geographic regions that we consider (NYC, NYS, and NJ). Second, $\hat{Z}$ is small and economically insignificant in New Jersey before the tax is introduced. Third, as discussed in online Appendix C, the estimates of $\hat{Z}$ are robust to the specification choices. Moreover, using data for New Jersey and constructing our counterfactual distribution using data from before the tax is introduced gives an estimate of $\hat{Z}$ somewhat smaller than the baseline maximum likelihood estimate and with large standard errors, but with a point estimate that is still economically significant.

This extensive-margin response highlights an important margin of efficiency loss due to the transaction tax notch. As discussed above, a positive estimate of $\hat{Z}$ suggests a very specific extensive-margin response, which we refer to as unraveling: some buyer-seller pairs who have a positive joint surplus under the tax (regions $B$ and $C$ of Figure 6) are exiting the market. This does not imply that these parties do not trade at all-buyers and sellers can continue to search and some of them may ultimately transact at different prices away from the bunching/ gap region-but it provides evidence that the market in the region just above the threshold is unraveling. Note that this is different from the usual extensive margin response in which buyer-seller pairs who would transact in absence of the tax find that the tax reduces their joint surplus below zero and so the sale does not occur. Our estimation procedure explicitly controls for this traditional extensive-margin response by allowing for a level shift (discontinuity) in the distribution above the notch.

Examining real estate listings data for New York City, we find suggestive evidence that the tax further disrupts the search process in a region above the notch. We interpret the presence of substantial bunching in the listings price (discussed above) as evidence that the tax influences seller search behavior. We also find that those who list just above the notch (between $\$ 1$ million and $\$ 1.075$ million) are still very likely to sell below $\$ 1$ million (see the relationship between listing and sale price in Figure A8 in the online Appendix), and are more likely to sell than those who list below the notch or much higher above the notch (Figure A9) despite spending more time on the market (Figure A10). Interestingly, those who list just above the notch are more likely to leave their original REBNY realtor and sell with another realtor or on their own (Figure A11), suggesting an additional margin of adjustment to the tax-saving on realtor fees to compensate for a lower price.

The evidence thus far points to extensive distortions to price, unraveling of the market, and some disruption of the matching process local to the transfer tax notch. However, many of these responses occur because of how the tax is implementedprices can adjust below the notch to avoid the tax and the notch creates specific local 


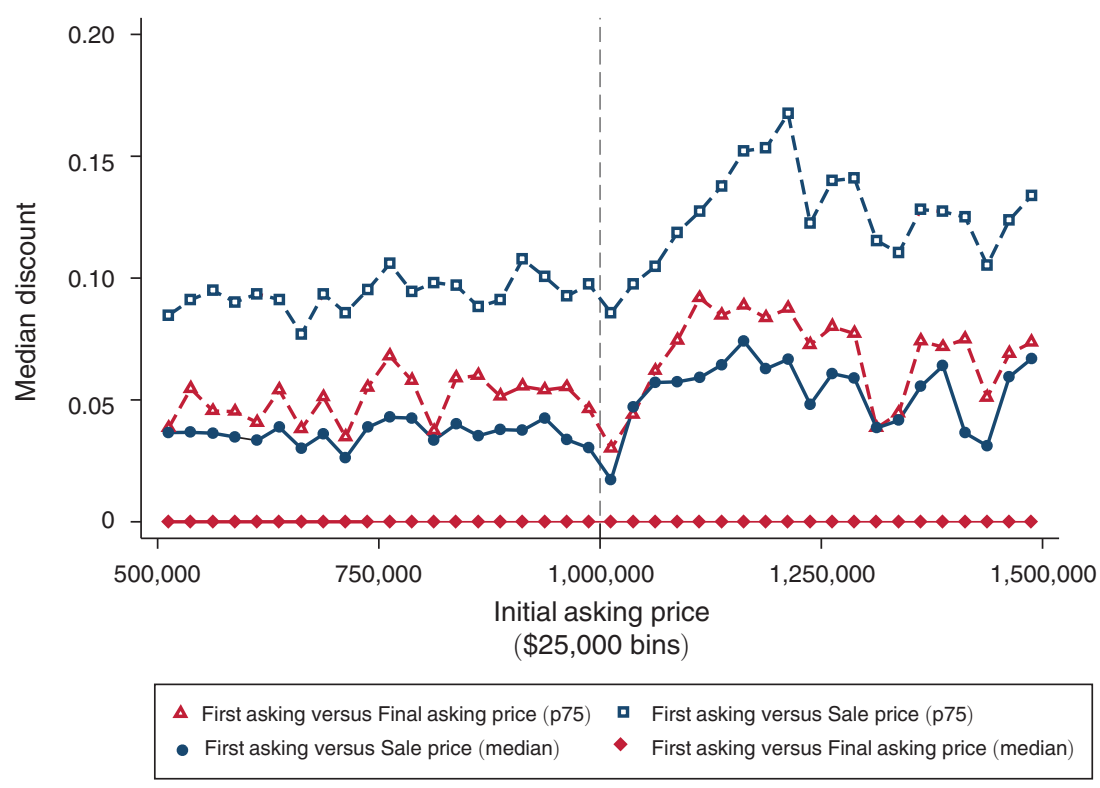

Figure 8. Median and 75th Percentile Price Discounts by Initial Asking Price

Note: Plot of the median and seventy-fifth percentile discount from initial asking to sale price $(=1$-final/initial) and initial asking to final asking price $(=1$-sale/initial) per $\$ 25,000$ initial-asking-price bin. Sample includes all closed REBNY-listed properties in the range $\$ 500,000-\$ 1,500,000$ that match to New York City DOF data.

Source: Data from REBNY listings

incentives for buyers and sellers to break matches. In what follows, we examine how the tax affects home sales more generally, away from the notch.

\section{Global Market Distortions}

In this section, we show evidence indicating that the transfer tax may distort the matching process everywhere above the notch. Conditional on initial listing price, sellers are taking larger discounts in the presence of the tax. While this higher discount could be explained by a shift in bargaining power or by endogenous listing prices, we find evidence that the efficiency of matches themselves is distorted by the tax. In particular, the variance of sale price conditional on property characteristics increases with the tax. While these results are largely descriptive-we must rely on observations below the threshold to form a counterfactual above- they do show sharp effects and, as discussed in Section IIID, we interpret this higher variance in selling price as a decrease in the efficiency of the matching process.

Price discounts, which we define as the percent drop from listing to sale price, increase under the transfer tax. Figure 8 shows that the discount from the initial price to the final advertised price (i.e., before a buyer is identified) and to the final sale price increase as the initial listing price moves above $\$ 1,000,000$. We present the median and seventy-fifth percentiles of the distribution of discounts (many listings are not revised) in the figures. The effect is not immediate at the $\$ 1,000,000$ 


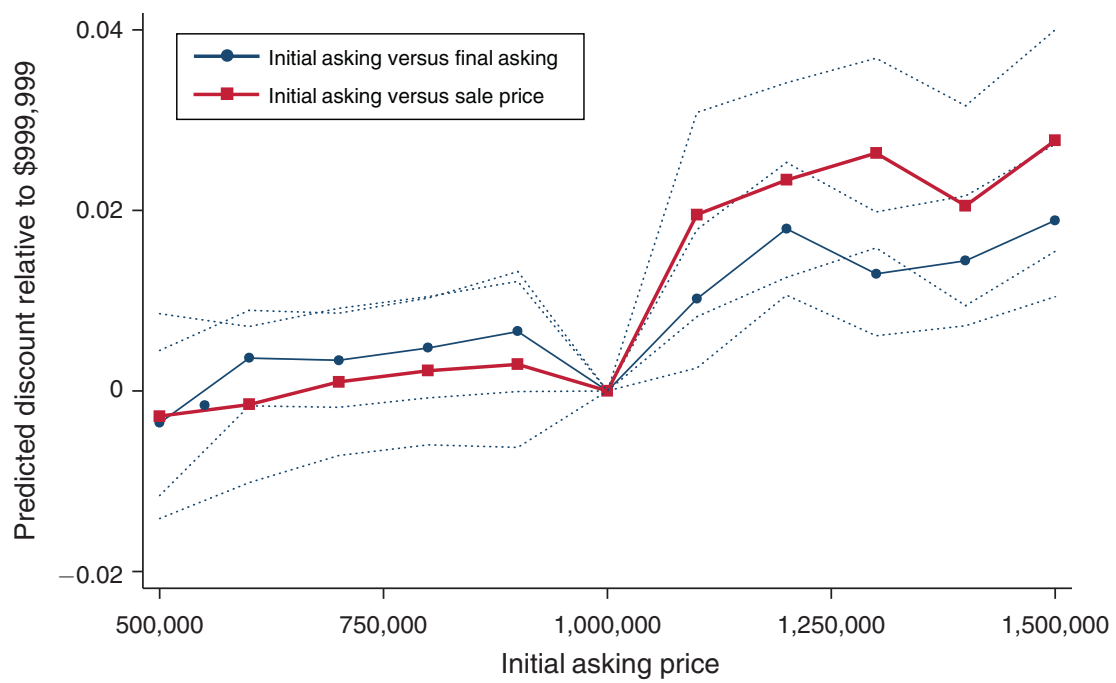

Figure 9. Predicted Price Discounts by Initial Asking Price (Relative to $\$ 1,000,000$ )

Notes: Plot of difference between predicted discounts by initial asking price and prediction at $\$ 1,000,000$ from regressions of discount (first to final price or first to sale price) on a linear spline in initial asking price with $\$ 100 \mathrm{~K}$ knots between $\$ 500,000$ and $\$ 1,500,000$. Dotted lines represent 95 percent confidence intervals.

threshold, because the tax applies to the sale price and not the initial price, and it is the latter that constitutes the running variable here: close to $\$ 1$ million a small discount is sufficient to bring the sale price below the notch. Interestingly, the increase is persistent well above the threshold—beyond $\$ 1.1 \mathrm{M}$ larger discounts persist, even though these discounts are generally not large enough to move the transaction below the notch. We find analogous evidence for the discount from final to sale price-see online Appendix Figure A12 - suggesting that the price response is slowly revealed and reinforced throughout the search process by distorting the initial prices, subsequent revisions and, finally, during the bargaining stage. ${ }^{27}$

We investigate the relationship between transfer taxes and price discounts more formally and find that the increase above the notch is significant and persistent. We regress the discount from initial asking price to sale price on a linear spline in initial asking price, with nodes at every multiple of $\$ 100,000$ (restricting the sample to listings with initial prices between $\$ 500,000$ and $\$ 1,500,000)$. We follow the same procedure for the discount from initial asking price to final asking price. We plot the difference between the predicted discount (first price and final price) at each node and the predicted discount at $\$ 1,000,000$ in Figure 9. These estimates show a significant jump in the price discounts at the notch that shows no signs of reversing before reaching $\$ 1.5$ million. ${ }^{28}$

\footnotetext{
${ }^{27}$ This can also be seen in Figure A13, in which we focus on the mean discounts from the initial price that allow us to decompose the response (but blur the response that is predominantly present at high quantiles). Roughly half of the response is due to price revisions and half due to discounts at the bargaining stage.

${ }^{28}$ The corresponding point estimates (and related slope estimates) are in online Appendix Table A4.
} 
There are several explanations for the increase in discounts. First, it could be that sale prices above the notch are not changing, but the response is driven by a change in asking prices (and we know from Section IV that asking prices respond to the tax). In this case, there could be little efficiency loss due to the tax. Second, it could be that the tax increases buyers' bargaining power. This may not entail any welfare loss due to the tax, but rather a redistribution of surplus from sellers to buyers. These two explanations still correspond to the tax affecting some aspects of behavior, although not necessarily the final outcomes. Alternatively, as we argue next, it could be that the tax disrupts the search process and reduces match quality with associated efficiency losses.

We find evidence consistent with transfer taxes disrupting the buyer-seller match process: conditional on seller characteristics, the tax increases the variance of sale prices. We investigate the relationship between asking prices and the variance of sale-prices with a two-stage spline estimation procedure. We first regress sale price on a linear spline in asking price (nodes at every $\$ 100,000$ between $\$ 500,000$ and $\$ 1,500,000)$. We then estimate by median regression the relationship between the squared residuals from this first stage and a linear spline in asking price. We estimate standard errors using a clustered bootstrap procedure. ${ }^{29}$ We find a significant increase in the variance of sale price as (initial or final) asking price crosses the $\$ 1,000,000$ notch. In Figure 10, we plot the predicted dispersion at the given node (from the two-stage spline procedure) relative to that at the notch. ${ }^{30}$ This increased dispersion is pronounced and persistent well above the notch. The estimates show that, in general, the predicted variance below the notch is very close to the predicted variance at $\$ 1,000,000$, while the variance of sale price conditional on asking price is significantly higher above the notch than below the notch. Even as asking price rises to $\$ 1,500,000$, the variance of sale price does not return to prenotch levels. This is inconsistent with asking prices and discounts simply scaling up without changes to other aspects of the matching process. As with the price discount, these estimates suggest that the real estate market is affected by the transfer tax even far above the notch - in the presence of the tax, asking price is a noisier signal of final sale price. ${ }^{31}$

In Section IIID, we argued that an increase in the dispersion in sale price conditional on seller characteristics implies a movement further away from the optimal allocation of assortative matching. An increase in the variance of sale price conditional on asking price is suggestive of such an efficiency loss, but it is not conclusive: the ideal measure is the variance of price conditional on seller type. Asking price is an imperfect proxy for seller type-if asking price is endogenous to the tax,

\footnotetext{
${ }^{29}$ We use median regression in the second stage, because squaring the residuals makes these specifications sensitive to outliers. The bootstrap is as follows: for each observation, we resample first-stage residuals from the 50 nearest observations (by listing price). We use these residuals and the first-stage predicted values to construct a bootstrap sample and re-estimate the two-step process. We iterate this process 999 to acquire the distribution of estimates.

${ }^{30}$ We present the numerical estimates of the difference between the predicted value at each node and the predicted value at $\$ 1,000,000$ in Table A5. The estimates are fairly consistent for both asking prices and are insensitive to the choice of quantile or mean regression in the first stage--see also Figure 10.

${ }^{31}$ This increase in dispersion is also confirmed in the raw data. In Figures A14 and A15 we plot the variance of sale price conditional on initial asking price and final asking price, respectively. In both cases, the variance of sale price increases above the notch.
} 


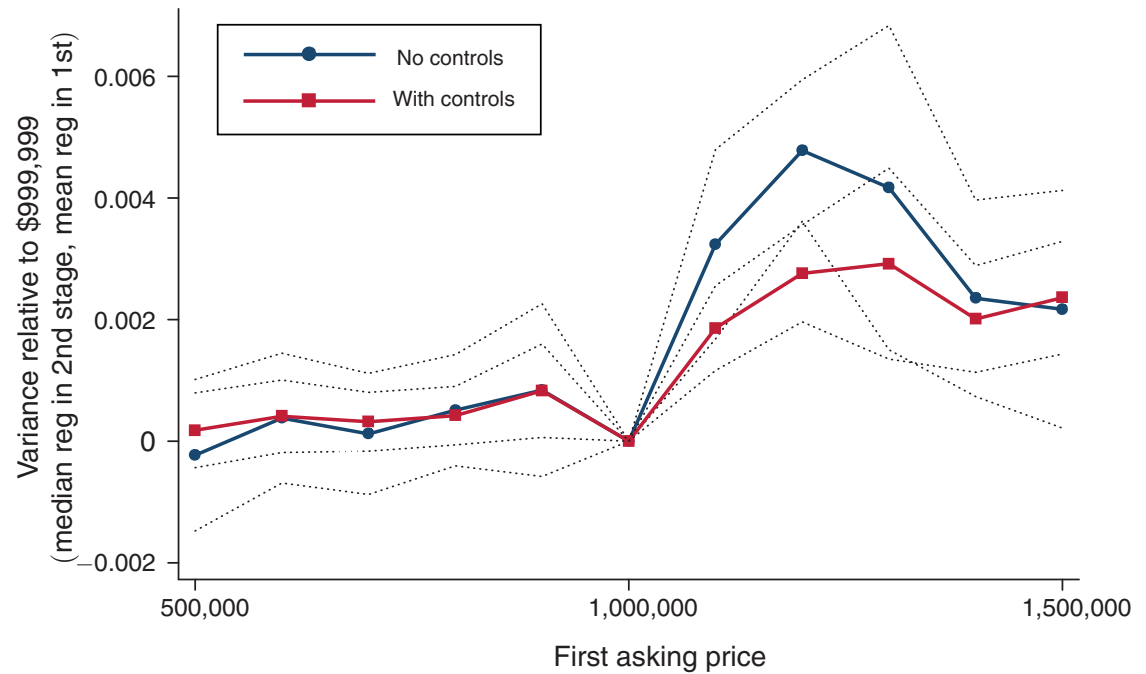

Figure 10. Predicted Dispersion of Log of Sale Price by Initial Asking Price (Relative to $\$ 1,000,000$ )

Notes: Plots of the difference between predicted values at given initial asking price and predicted value at $\$ 1,000,000$ from the following procedure. The log of sale price is regressed on a linear spline in the log of initial asking price with $\$ 100,000$ knots between $\$ 500,000$ and $\$ 1,500,000$. Squared residuals from this first stage are then regressed on a linear spline in log of initial asking price (using median regression; results are sensitive to outliers). Controls in the indicated results include year of sale, zipcode, building type, whether the sale is of a new unit, and the log of years since construction. Dotted lines represent 95 percent confidence intervals from 999 wild bootstrap replications of the two-stage procedure, resampling residuals in the first stage by asking-price clusters.

the increase in variance may be driven by a change in the composition of sellers who list at each price.

We repeat the two-step estimates of sale-price variance versus asking price including controls for property characteristics, in order to better approximate the variance of sale price conditional on seller type. In both stages we control for year-of-sale fixed effects, zip code fixed effects, building type (single-family home, multi-family home, apartment in walkup, apartment in elevator building, etc.), whether the sale is of a new unit, and the log of years since construction (plus an indicator for missing years since construction). We plot the results from this procedure in Figure 10. Including these controls somewhat reduces the effect of the tax on the variance of sale price, suggesting that endogeneity of listing prices may have influenced the previous estimates, but the difference is not large and generally not statistically significant. In particular, there is still a significant increase in the dispersion of sale price above the notch. We interpret this increase as evidence that the transfer tax reduces efficiency of the housing market by disrupting the matching process.

\section{Conclusions}

Our empirical analysis demonstrates how a notched transaction tax affects the distribution of housing sales by creating bunching below the notch, a large gap in the distribution above the notch, and distorts the relationship between asking price and sale price. The price responses that we identify suggest that sellers local to the threshold take large price cuts-greater than the cost of the tax-although this may 
partially be driven by quality adjustments. The finding of a gap above the notch that is larger than the number of sales bunching at the threshold-even after controlling for the usual extensive-margin effect-suggests that there are productive transactions that do not occur because of the notched tax. We show that there is bunching in the distribution of residential listing prices and an effect of the tax on discounts, both of which indicate that not just the final price, but also some aspects of the search process, are affected by the tax. Finally, we find that in the presence of transaction taxes the relationship between seller asking price and final sale price weakens, and that this persists when we control for property characteristics. This effect extends far above the threshold. We interpret this increase in price dispersion as a movement away from the efficient allocation of positive assortative matching in the housing market and as revealing the distortion due to taxation globally. Hence, we conclude that our analysis of real-estate transaction tax notches reveals substantial price response local to tax thresholds, that a notched tax crowds out productive transactions, and that transaction taxes may increase search-related inefficiencies.

That we find substantial distortions due to the design of the transaction taxes in New York and New Jersey ( 0.7 percent of all transactions are eliminated due to the threshold) raises the question of why notched taxes are present in the first place. One of the few general results of the optimal income tax literature is that the marginal tax rate should be lower than 100 percent (no notches). Indeed, our bunching estimates show that the transfer tax threshold leads to a substantial response and loss of revenue. Moreover, unraveling adds efficiency and revenue costs. Phasing in the mansion tax, which is likely administratively feasible, would eliminate these inefficiencies. Still, phasing in would not eliminate all distortions: an extensive margin response may be present and one of our findings is that search is affected even far from the threshold. One might ask, then, why have a progressive transfer tax is in the first place. Public finance theory, going back to the Atkinson-Stiglitz result, suggests that such an instrument is useful if it can push redistribution beyond what can be achieved via an income tax (a tool which New York State, New York City, and New Jersey all have in place). The real estate market raises an additional issue though: some investors may be nonresidents, so that resources invested in real estate need not be reachable by income taxes. Still, while a transfer tax might indeed hit nonresidents, the same would be true about general property taxes, which avoid many of the inefficiencies we identify herein. One redeeming quality of the transaction tax is that it will disproportionately affect more frequently traded properties. This feature is appealing if frequency of trading varies for different groups of purchasers.

Our evidence of exit from markets near the tax threshold raises important issues for implementation and interpretation of studies relying on bunching at notches for identification. To date, most of this literature has assumed one-sided markets and abstracted from extensive-margin responses. Our framework highlights that there are two different types of exit from markets. One is standard-transactions with low surplus do not take place. In the income tax context, this is akin to the labor force participation decision. ${ }^{32}$ The second type of exit, which has not been previously

\footnotetext{
${ }^{32}$ See Marx (2013) for explicit modeling of this decision to exit the market.
} 
recognized in this literature, is unraveling of the market near the notch that corresponds to destroying productive matches. Both of these responses imply that bunching does not fully characterize the consequences of a notch. While in some contexts (e.g., an income tax notch at a high value) it is reasonable to ignore the first type of extensive-margin response, the second type of response is likely to be intrinsic to any matching context in which parties have an option to continue search (e.g., firms may continue searching for a worker willing to accept a wage below the notch; employees may make different occupational choices). The possibility of this second type of response undermines the assumption that the excess mass bunching at the threshold is identical to the missing mass in the gap (as in Kleven and Waseem 2013). Our empirical framework relaxes this assumption and allows us to explicitly test for exit local to the notch.

More generally, our results suggest that taxes may introduce inefficiencies into other search markets. Labor markets are, perhaps, the most obvious example of a market with nontrivial search costs where matches are subject to taxation. Many labor-market regulations follow notched designs, such as notched income and wage taxation or requirements to provide health insurance or comply with Value Added Tax if the number of employees crosses a given threshold. That firms might face such discrete costs to increasing scale may lead not simply to supply- or demand-side adjustments, but perhaps to the destruction of equilibrium opportunities that require costly search - in the same way that productive real estate matches are discouraged near the transaction tax notch. Moreover, our finding that transaction taxes increase search-related inefficiencies well above the threshold suggests that even non-notched policies may lead to less efficient worker-firm matches. Of course, the housing market differs from the labor market in ways that may make the mechanisms we study particularly pronounced. Firstly, the availability of alternative margins of adjustment affects the ease of moving below the tax threshold. Secondly, the housing market is a "spot" market where the current price determines tax treatment; this is not necessarily the case in labor markets, where contracts may be long lasting and as earnings adjust over time they move further away from the notch. Nonetheless, our results underscore the importance of considering how taxation affects search, especially in the context of policies that follow a threshold design.

\section{ApPendix: BARgaining Model}

To identify buyer-seller pairs that move to the notch, we compare maximized surplus above the notch to surplus when price is at the notch. Surplus at the notch is given by $\beta \ln (H-s)+(1-\beta) \ln (b-H)$, while maximized surplus when the tax is due is given by $\beta \ln (\beta(b-s-T))+(1-\beta) \ln ((1-\beta)(b-s-T))$. Transactions in this category that sell at the threshold satisfy:

$$
\begin{aligned}
f(b, s ; \beta) \equiv & \beta \ln (H-s)+(1-\beta) \ln (b-H)-\beta \ln (\beta) \\
& -(1-\beta) \ln (1-\beta)-\ln (b-s-T) \geq 0 \\
(1-\beta) s+ & \beta b \geq H+\beta T \text { and } b-T-s \geq 0, b \geq H+T, s \leq H
\end{aligned}
$$


at the notch. That is, the surplus at the threshold has to be higher than under the alternative of selling with the tax, and the nontrivial case corresponds to transactions with positive surplus that could otherwise sell at a price higher than the threshold. We show the following results:

LEMMA A1: Fix $0<\beta<1$ and consider matches $(b, s)$ that satisfy $p(b, s) \geq H+\beta T, b-T-s \geq 0, b \geq H+T$, and $0 \leq s \leq H$

(i) For any value of $0 \leq s \leq H$ there exists $b(s)>-\frac{(1-\beta)}{\beta} s+\frac{H+\beta T}{\beta}$ such that $f(b(s), s ; \beta)=0$.

(ii) Matches $(b, s)$ that satisfy $b \in\left[-\frac{(1-\beta)}{\beta} s+\frac{H+\beta T}{\beta}, b(s)\right]$ locate at the notch and those with $b>b(s)$ sell with the tax at $p(b, s)-\beta T$.

(iii) Matches $\left(b^{\prime}, s^{\prime}\right)$ that would otherwise sell at the same price as $(b(s), s)$ (i.e., $\left.p\left(b^{\prime}, s^{\prime}\right)=p(b(s), s)\right)$ sell at the notch when $s^{\prime} \leq s$ and sell with the tax otherwise.

(iv) $b(0)$ is finite, and matches $(b, s)$ that absent the tax would sell at prices higher than the corresponding price $p(b(0), 0)=\beta b(0)$ will never bunch.

\section{PROOF:}

For part (i) and (ii) note that for a transaction that would otherwise sell exactly at $H+\beta T$ the notch is preferred so that $f\left(-\frac{(1-\beta)}{\beta} s+\frac{H+\beta T}{\beta}, s ; \beta\right) \geq 0$; that $\frac{\partial f}{\partial b}$ $=\frac{1-\beta}{b-H}-\frac{1}{b-s-T}=-\frac{H+\beta T-(\beta b+(1-\beta) s)-T}{(b-H)(b-s-T)}<0$ because $(1-\beta) s+$ $\beta b \geq H+\beta T$; and finally that $\lim _{b \rightarrow \infty} f(b, s ; \beta)=\beta \ln (H-s)-\beta \ln (\beta)-$ $(1-\beta) \ln (1-\beta)+(1-\beta) \ln \left(\frac{b-H}{b-s-T}\right)-\beta \ln (b-s-T)=-\infty$ because all but last term converge to finite values as $b$ increases. Hence, for each $0 \leq s$ $\leq H$, there is $b(s)$ that solves $f(b(s), s ; \beta)=0$, and $b(s)$ separates positive from negative values of $f(b, s ; \beta)$.

Part (iii): to evaluate the effect of a change in $s$ holding $p(b, s)$ constant, substitute $b^{\prime}=-\frac{1-\beta}{\beta} s^{\prime}+\frac{p(b(s), s)}{\beta}$ into $f(b, s ; \beta)$ and totally differentiate with respect to $s$ to obtain $\frac{d f}{d s}=-\frac{\beta}{H-s}-\frac{(1-\beta)^{2}}{\beta(b-H)}+\frac{1}{\beta b-s-T}=\frac{1}{\beta}\left(\frac{1}{b-s-T}-\right.$ $\left.\frac{\beta}{(H-s) / \beta}-\frac{1-\beta}{(b-H) /(1-\beta)}\right)$. Note that convexity of $\frac{1}{x}$ implies that $\frac{\beta}{(H-s) / \beta}+$ $\frac{1-\beta}{(b-H) /(1-\beta)} \leq \frac{1}{\beta(H-s) / \beta+(1-\beta)(b-H) /(1-\beta)}=\frac{1}{b-s}$ and since $\frac{1}{b-s}<$ $\frac{1}{b-s-T}$ we have $\frac{d f}{d s}>0$.

Part (iv): finiteness of $b(0)$ follows from part (i). When $p(b, s)>\beta b(0)$, then there is $b^{\prime}<b$ such that $p\left(b^{\prime}, s\right)=\beta b(0)=p(b(0), 0)$. Part (iii) implies that $\left(b^{\prime}, s\right)$ sells with the tax because $s \geq 0$. Because $b>b^{\prime}, \frac{\partial f}{\partial b}<0$ then implies that $(b, s)$ also does not locate at the notch. 
The lemma establishes the existence and shape of the schedule $b(s)$, which is marked by a solid line in Figure 6. Given the seller reservation value, matches with buyers to the left of this schedule bunch at the notch, while those above it sell with the tax. Parts (i) and (ii) of the lemma establish that $b(s)$ exists and is unique for any $s$ lower than the threshold. Part (iii) shows that the slope of $b(s)$ is flatter than that of the constant-price schedules, and Part (iv) shows that the schedule $b(s)$ intersects the horizontal axis at some finite value so that for sufficiently high original prices transactions will never bunch. We restate this last observation in the following corollary:

COROLLARY A1. Transactions at the notch satisfy $H \leq p(b, s) \leq \beta b^{*}(\beta)<\infty$, where $b^{*}(\beta)$ is defined as $f\left(b^{*}(\beta), 0 ; \beta\right)=0$ or, explicitly, it solves $\beta \ln (H)+$ $(1-\beta) \ln (b-H)-\beta \ln (\beta)-(1-\beta) \ln (1-\beta)-\ln (b-T)=0$.

The corollary follows from part (iv) of the lemma. As the original price increases, the attractiveness of the notch declines so that only transactions with sufficiently high overall surplus (sufficiently low reservation price of the seller) continue to bunch. For some price, even the seller with zero reservation value will no longer agree to bunch at the notch and hence no matches corresponding to higher $p(b, s)$ will bunch either. The bound in the corollary depends on $\beta$. Interestingly, one can show that there is a uniform and finite bound for all $\beta$, so that transactions above some finite price are never induced to bunch, regardless of the value of $\beta$.

THEOREM A1: For any $\beta>0$, transactions at the notch satisfy $H \leq p(b, s)$ $\leq \beta b^{*}(\beta)<x(0)<\infty$, where $f\left(b^{*}(\beta), 0 ; \beta\right)=0$ and $x(\beta) \equiv \beta\left(b^{*}(\beta)-T\right)$ for any $\beta \in(0,1), x(0)=\lim _{\beta \rightarrow 0} x(\beta)$ and the value of $x(0)$ is the solution to $\ln (H)-\ln (x)-\frac{H-T}{x}+1=0$.

\section{PROOF:}

In what follows we change variables as $x=\beta(b-T)$ (because it turns out that $\left.\lim _{\beta \rightarrow 0} b^{*}(\beta)=\infty\right)$. Note also that part (i) of the Lemma applied to $\left(b^{*}(\beta), 0\right)$ implies that $x(\beta)=\beta\left(b^{*}(\beta)-T\right)>H$ so that we don't need to consider $x \leq H$. Define the net benefit of locating at the notch for a given $x$ as $g(x, \beta)$ $\equiv f\left(\frac{x}{\beta}+T, 0 ; \beta\right)$ or more explicitly

$$
\begin{aligned}
g(x, \beta) \equiv & \beta \ln (H)+(1-\beta) \ln \left(\frac{x-\beta(H-T)}{\beta}\right) \\
& -\ln \left(\frac{x}{\beta}\right)-\beta \ln (\beta)-(1-\beta) \ln (1-\beta) \\
= & \beta \ln (H)-\ln (x)+(1-\beta)[\ln (x-\beta(H-T))-\ln (1-\beta)] .
\end{aligned}
$$

We are interested in properties of $x(\beta)$ that solves $g(x(\beta), \beta)=0$.

Denote by $x^{*}$ the solution of $\ln (H)-\ln (x)-\frac{H-T}{x}+1=0 . x^{*}$ is independent of $\beta$ and finite. Note that $g(x, \beta)$ is continuous in $x$ on $\left[H, x^{*}\right]$ and that $g(H, \beta)$ 
$=(1-\beta) \ln \left[\frac{(1-\beta) H+\beta T}{(1-\beta) H}\right]>0$ and $g\left(x^{*}, \beta\right)=\beta \ln (H)-\beta \ln \left(x^{*}\right)+(1-\beta)$

$\times \ln \left[\frac{x^{*}-\beta(H-T)}{(1-\beta) x^{*}}\right]<\beta \ln (H)-\beta \ln \left(x^{*}\right)+(1-\beta)\left[\frac{x^{*}-\beta(H-T)}{(1-\beta) x^{*}}-1\right]$

$=\beta\left[\ln (H)-\ln \left(x^{*}\right)-\frac{H-T}{x^{*}}+1\right]=0$ (using $\ln (x)<x-1$ and the definition of $\left.x^{*}\right)$. Hence, for every $\beta, g(x, \beta)=0$ has a solution on $\left(H, x^{*}\right)$ and, in particular, $\lim _{\beta \rightarrow 0} x(\beta)$ has to be finite.

For all $\beta \in(0,1), x(\beta)$ solves $g(x(\beta), \beta)=0$ so that $g_{x} x^{\prime}(\beta)+g_{\beta}=0$. Note that $g_{x}=\frac{1-\beta}{x-\beta(H-T)}-\frac{1}{x}=-\frac{\beta(x+H-T)}{x(x-\beta(H-T))}$. Clearly, for any $x>H-T$ we have $\lim _{\beta \rightarrow 0} g_{x}=0$. Because $\lim _{\beta \rightarrow 0} x(\beta)>H-T$ and is finite, we also have $\lim _{\beta \rightarrow 0} g_{x}(x(\beta), \beta)=0$ and $\lim _{\beta \rightarrow 0}\left|x^{\prime}(\beta)\right|<\infty$. Consequently, 0 $=\lim _{\beta \rightarrow 0} g_{x} x^{\prime}(\beta)+g_{\beta}=\lim _{\beta \rightarrow 0} g_{\beta}(x(\beta), \beta)=\lim _{\beta \rightarrow 0}\{\ln (H)-\ln (x(\beta)-$ $\left.\beta(H-T))+\ln (1-\beta)-\frac{(1-\beta)(H-T)}{x(\beta)-\beta(H-T)}+1\right\}=\ln (H)-\ln (x(0))-\frac{H-T}{x(0)}+1$ as in the statement of the proposition.

Example: When $H=1,000,000, T=10,000$, and $x(0) \approx \$ 1,144,717$, transactions that absent the tax would sell above this value will not bunch regardless of the value of $\beta$.

The gray dashed line on Figure 6 illustrates the bound, which corresponds to the price $x(0)$. As $\beta$ changes, the slope of the corresponding line will change but it will always correspond to the price of $x(0)$. The sharp bound for a given $\beta$ (the light diagonal line) always lies to the left of this uniform bound and converges to it as $\beta$ tends to zero. While this bound is irrelevant given $\beta$, it is of natural interest when $\beta$ is unknown.

Proportional Tax.-While considering a lump-sum tax simplifies the analysis, transaction taxes, including the mansion tax, are typically proportional. However, the results are only slightly affected when the tax is proportional. Intuitively, incentives for bunching at the notch are always determined by the level of the loss due to taxation (both due to the tax itself and any distortionary impact it might cause), rather than the rate of the tax (this is standard intensive/extensive margin distinction). The proportional tax induces re-ranking, but retains qualitative features of the solution described above. In the presence of the proportional tax the Nash bargaining outcome is given by $p^{s}=q(b, s ; t) \equiv \beta \frac{b}{1+t}+(1-\beta) s$, where $q(b, s, t)$ denotes the seller's given types and the marginal tax rate, and $p^{b}=(1+t) p^{s}=\beta b+(1-\beta) s(1+t)$ so that the overall surplus from the transaction is equal to

$$
\beta \ln (\beta)+(1-\beta) \ln (1-\beta)+\ln (b-s(1+t))-\beta \ln (1+t) .
$$

As in the case of the lump-sum tax, the price $q(b, s ; t)$ is linear in types so that the locus of matches with constant price remains linear (although the slope is affected by the tax rate), as in Figure 6. 
It is also straightforward to show an analogous result to Lemma A1 for the proportional case. Holding $s$ constant, the net benefit to locate at the notch declines with $b$ and becomes negative for sufficiently high $b$ (because $(1-\beta) \ln (b-H)-$ $\ln (b-s(1+t))$ declines in $b)$. Thus, a schedule analogous to $b(s)$ also exists in the proportional case. Similarly to part (iii) of the Lemma, the net surplus from switching to the notch declines in $s$ holding $q(b, s ; t)$ constant, so that the price corresponding to $b(0)$ has to constitute the upper bound of the region affected by the presence of the tax.

Finally, there is a straightforward relationship between the bounds corresponding to the lump-sum and proportional tax. To see it, note that for a given match $(b, s)$ the value of locating at the notch is the same regardless of whether the tax is proportional or lump-sum because that allocation does not involve any tax. Consider $s=0$, and the value of $b, b^{*}(\beta ; T)$, that as before represents a match that is indifferent between locating at the notch given the value of $T$. Simple inspection of the surplus for the lump-sum and proportional tax cases shows that the indifference will hold for the proportional tax as well (because the surplus will be the same as under the lump-sum tax) when the marginal tax rate is such that $\ln \left(b^{*}(\beta ; T)\right)-\beta \ln (1+t)$ $=\ln \left(b^{*}(\beta ; T)-T\right)$ so that $(1+t)^{\beta}=\frac{b^{*}(\beta ; T)}{b^{*}(\beta ; T)-T}$. Thus, given $\beta$, the bounds for $T$ map into the bounds for $t$ by this relationship.

Theorem A1 describes a uniform bound for prices corresponding to transactions that might be affected by the lump-sum tax of $T$. Because bounds for proportional and lump-sum taxes are related for any $\beta$, that theorem can be adapted to identify the corresponding bound in the proportional tax case.

THEOREM A2: Given marginal tax rate $t$, define $x^{*}$ as the solution to $\ln (H)-$ $\ln (x)-\frac{H-x \ln (1+t)}{x}+1=0$. For any $\beta>0$, transactions at the notch need to satisfy $H \leq q(b, s ; t) \leq x^{*} /(1+t)<\infty$, and $x^{*}$ is the lowest such bound.

\section{PROOF:}

To obtain the analogue of Theorem A1, recall that given $T$ the theorem established the existence of the upper bound of undistorted prices below which transactions (might) relocate to the notch. Denote by $x(T)$ the uniform bound for $\beta b$ identified in Theorem A1 for a given value of $T$. For any $\beta$ and tax rate $t$ that satisfy $\ln (x(T) / \beta)-\beta \ln (1+t) \geq \ln (x(T) / \beta-T), x(T)$ would equal or exceed the undistorted price bound for transactions relocating to the notch under proportional tax. We will find the value of $t$ for which $x(T)$ is the smallest such a bound for any positive $\beta$. Rewrite this inequality as $\ln (x(T))-\beta \ln (1+t) \geq \ln (x(T)-\beta T)$. Note that it holds with equality when $\beta=0$. Taking derivatives of both sides with respect to $\beta$, we obtain $-\ln (1+t)$ and $-\frac{T}{x(T)-\beta T}$ respectively. In order for the inequality to hold in the neighborhood of $\beta=0$, we need to have $\ln (1+t)$ $\leq \frac{T}{x(T)-\beta T}$ for small $\beta$, and when that's the case the inequality will hold for any value of $\beta$ because the left-hand side is constant while the right-hand side is increasing in $\beta$. The bound will be tight when we do in fact have equality at $\beta=0$ so that $\ln (1+t)=\frac{T}{x(T)}$. Accordingly, when this relationship holds, substituting 
$x \ln (1+t)$ for $T$ in the equation defining $x(0)$ in Theorem A1 (which leads to the formula in the statement of the proposition) and solving for $x$ will yield exactly the same solution $x^{*}(t)$. Finally, this procedure shows that when $s=0$, only matches with $b \leq x^{*}(t) / \beta$ may bunch. Correspondingly, only transactions that satisfy $q(b, s ; t) \leq q\left(x^{*}(t) / \beta, 0 ; t\right)=x^{*}(t) /(1+t)$ might bunch.

Clearly, the value $x^{*}$ that solves this formula is also the solution to the equation in Theorem A1 when $T=x^{*} \ln (1+t)$, and the proof makes it clear that this is the right "conversion" between the proportional and lump-sum tax cases. The theorem provides a bound in terms of prices distorted by the tax $q(b, s, t)$. However, because $q(b, s, t)(1+t) \geq q(b, s, 0)$ it also provides a (weaker) bound in terms of prices that are not distorted $(t=0)$ : transactions that bunch need to satisfy $H \leq q(b, s ; 0)$ $\leq x^{*}<\infty$.

Example: For the New York and New Jersey mansion tax, $H=1,000,000$, $t=0.01, x^{*} \approx \$ 1,155,422$. Hence, regardless of the value of $\beta$, transactions that absent the tax would occur at prices above $\$ 1,155,422$ will never bunch, while those that would occur below might bunch. Transactions that do bunch, would otherwise sell (in the presence of the tax) at no more than $x^{*} /(1+t)=\$ 1,143,982$. This is the same bound as the one corresponding to the lump-sum tax of $\$ 1,155,422 \cdot \ln (1+0.01) \equiv \$ 11,496.83$

\section{REFERENCES}

Benjamin, John D., N. Edward Coulson, and Shiawee X. Yang. 1993. "Real estate transfer taxes and property values: The Philadelphia story.” Journal of Real Estate Finance and Economics 7 (2): 151-57.

Bernheim, Douglas B., and Jonathan Meer. 2013. "Do Real Estate Brokers Add Value When Listing Services Are Unbundled?” Economic Inquiry 51 (2): 1166-82.

Besley, Timothy, Neil Meads, and Paolo Surico. 2013. "The Incidence of a Transactions Tax: Evidence from a Stamp Duty Holiday." Unpublished.

Best, Michael, and Henrik Jacobsen Kleven. 2013. "Property Transaction Taxes and the Housing Market: Evidence from Notches and Housing Stimulus in the UK." http://www.iza.org/en/ papers/2481_29012013.pdf.

Carrillo, Paul E. 2012. "An Empirical Stationary Equilibrium Search Model of the Housing Market." International Economic Review 53 (1): 203-34.

Carrillo, Paul E., and Jaren C. Pope. 2012. "Are Homes Hot or Cold Potatoes? The Distribution of Marketing Time in the Housing Market." Regional Science and Urban Economics 42 (1): 189-97.

Dachis, Ben, Gilles Duranton, and Matthew A. Turner. 2012. "The Effects of Land Transfer Taxes on Real Estate Markets: Evidence from a Natural Experiment in Toronto." Journal of Economic Geography $12(2): 327-54$.

Doyle Jr., Joseph J., and Krislert Samphantharak. 2008. "\$2.00 Gas! Studying the Effects of a Gas Tax Moratorium." Journal of Public Economics 92 (3-4): 869-84.

-Genesove, David, and Lu Han. 2012. "Search and Matching in the Market for Existing Homes." Journal of Urban Economics 72 (1): 31-45.

Genesove, David, and Christopher Mayer. 2001. "Loss Aversion and Seller Behavior: Evidence from the Housing Market." Quarterly Journal of Economics 116 (4): 1233-60.

Han, Lu, and William Strange. 2012. "What is the Role of the Asking Price for a House?" http://erwan. marginalq.com/HULM13s/ws.pdf.

Han, Lu, and William Strange. 2014. "Bidding Wars for Houses.” Real Estate Economics 42 (1): 1-32.

Hastings, Justine, and Ebonya Washington. 2010. "The First of the Month Effect: Consumer Behavior and Store Responses.” American Economic Journal: Economic Policy 2 (2): 142-62.

Haurin, Donald R., Jessica L. Haurin, Taylor Nadauld, and Anthony Sanders. 2010. "List Prices, Sale Prices and Marketing Time: An Application to US Housing Markets." Real Estate Economics 38 (4): 659-85. 
Jia, Panle, and Parag A. Pathak. 2010. "The Impact of Commissions on Home Sales in Greater Boston." American Economic Review 100 (2): 475-79.

-Kleven, Henrik J., and Mazhar Waseem. 2013. "Using Notches to Uncover Optimization Frictions and Structural Elasticities: Theory and Evidence from Pakistan." Quarterly Journal of Economics 128 (2): 669-723.

Kopczuk, Wojciech, and David Munroe. 2015. "Mansion Tax: The Effect of Transfer Taxes on the Residential Real Estate Market: Dataset." American Economic Journal: Economic Policy. http://dx.doi. org/10.1257/pol.20130361.

Levitt, Steven D., and Chad Syverson. 2008. "Market Distortions When Agents Are Better Informed: The Value of Information in Real Estate Transactions." Review of Economics and Statistics 90 (4): 599-611.

-Marion, Justin, and Erich Muehlegger. 2011. "Fuel Tax Incidence and Supply Conditions.” Journal of Public Economics 95 (9-10): 1202-12.

Marx, Benjamin M. 2013. "Regulatory Hurdles and Growth of Charitable Organizations: Evidence from a Dynamic Bunching Design.” Unpublished.

-Merlo, Antonio, and Francois Ortalo-Magne. 2004. "Bargaining Over Residential Real Estate: Evidence from England." Journal of Urban Economics 56 (2): 192-216.

- Mishra, Prachi, Arvind Subramanian, and Petia Topalova. 2008. "Tariffs, enforcement, and customs evasion: Evidence from India." Journal of Public Economics 92 (10-11): 1907-25.

Persson, Petra. 2014. "Social Insurance and the Marriage Market." Unpublished.

- Rothstein, Jesse. 2010. "Is the EITC as Good as an NIT? Conditional Cash Transfers and Tax Incidence." American Economic Journal: Economic Policy 2 (1): 177-208.

-Saez, Emmanuel. 2010. "Do Taxpayers Bunch at Kink Points?" American Economic Journal: Economic Policy 2 (3): 180-212.

- Saez, Emmanuel, Manos Matsaganis, and Panos Tsakloglou. 2011. "Earnings Determination and Taxes: Evidence from a Cohort Based Payroll Tax Reform in Greece." Quarterly Journal of Economics 127 (1): 493-533.

- Saez, Emmanuel, Joel Slemrod, and Seth H. Giertz. 2012. "The Elasticity of Taxable Income with Respect to Marginal Tax Rates: A Critical Review." Journal of Economic Literature 50 (1): 3-50.

-Slemrod, Joel B. 1990. "Optimal Taxation and Optimal Tax Systems." Journal of Economic Perspectives 4 (1): 157-78.

Slemrod, Joel B. 2010. "Buenas Notches: Lines and Notches in Tax System Design.” http://webuser. bus.umich.edu/jslemrod/pdf/Buenas\%20Notches\%20090210.pdf.

Slemrod, Joel B., Caroline Weber, and Hui Shan. 2012. "The Lock-in Effect of Housing Transfer Taxes: Evidence from a Notched Change in D.C. Policy." http://webuser.bus.umich.edu/jslemrod/ pdf/Buenas\%20Notches\%20090210.pdf.

-Van Ommeren, Jos, and Michiel Van Leuvensteijn. 2005. "New Evidence of the Effect of Transaction Costs on Residential Mobility." Journal of Regional Science 45 (4): 681-702. 